\title{
Colores verdaderos. Una panorámica fenomenológica
}

\author{
Alejandro G. Vigo \\ Departamento de Filosofía \\ Instituto Cultura y Sociedad (ICS) \\ Universidad de Navarra \\ avigo@unav.es
}

Der Phänomenologe muß in gewisser Weise die Anlage eines Künstlers und der, der die Wahrnehmung untersucht, Anlage zum Maler haben.

Wilhelm Schapp

Daß es Farben "an sich" nicht gibt, weiß ja heute schon jedes Kind.

Es bedarf philosophischer Phänomenologie, um zu begreifen,

daß es sie sehr wohl gibt.

Robert Spaemann

\section{Las concepciones fenomenológicas del color y su orientación general}

La referencia a las «concepciones fenomenológicas» del color puede tomarse en un sentido estrecho o bien en uno más amplio. En sentido estrecho, la expresión remite a las concepciones elaboradas, a partir de las primeras décadas del siglo $x \mathrm{x}$, por autores que reconocen, de uno u otro modo, su pertenen- 
cia a lo que se ha dado en llamar el «movimiento fenomenológico» (H. Spiegelberg), iniciado por Edmund Husserl (18591938). En un sentido más amplio, la expresión puede referirse también a concepciones elaboradas por autores que no pertenecen a dicho "movimiento", ya sea por tratarse de autores de épocas precedentes, incluso muy alejadas del siglo $x x, 0$ bien por tratarse de autores que, siendo contemporáneos o posteriores a dicha época, muestran un perfil filosófico diferente, cuya especificidad no puede ser adecuadamente caracterizada en términos de la relación que pudieran mantener con la fenomenología. En estos casos, se trataría de concepciones que, ya sea por su orientación general, ya sea por los elementos de detalle que contienen, o bien por ambas cosas, muestran una orientación similar a la que define a las concepciones elaboradas por genuinos representantes del «movimiento fenomenológico». Así, por citar sólo unos pocos casos, se puede argüir razonablemente que las concepciones del color elaboradas por autores como Aristóteles o Goethe podrían ser caracterizadas, al menos en referencia a algunos de sus rasgos característicos, como concepciones fenomenológicas en el sentido más amplio de la expresión o, si se prefiere, como concepciones fenomenológicas avant la lettre, mientras que, entre las concepciones de autores del siglo xx que no poseen extracción fenomenológica, la esbozada por Wittgenstein, por ejemplo, presenta también una serie de aspectos que la hacen tendencialmente convergente con las concepciones fenomenológicas, en el sentido estrecho del término.

Como es obvio, el sentido amplio de la expresión «concepciones fenomenológicas» abre todo un espectro de posiciones que no puede ser abordado razonablemente aquí. Por lo mismo, consideraré en lo que sigue exclusivamente algunas de las más representativas entre las concepciones fenomeno- 
lógicas, en el sentido estrecho del término. Más precisamente, consideraré primero las concepciones pertenecientes a autores situados en la cercanía inmediata de Husserl, especialmente la de Wilhelm Schapp, que destaca por su altísimo nivel de diferenciación, y la de Adolf Reinach, que representa, más bien, una reflexión ocasional, de carácter fragmentario. A continuación, pasaré revista de modo sumario a diversas concepciones elaboradas en el ámbito de la psicología por representantes de corrientes psicológicas afines a la fenomenología, tales como la «psicología de la forma» (Gestaltpsychologie) y la «psicología del pensamiento» (Denkpsychologie). A continuación, consideraré las dos concepciones más representativas en la fenomenología de la segunda mitad del siglo xx: la de Maurice MerleauPonty, que recoge buena parte de los desarrollos precedentes, y la de Hermann Schmitz, mucho menos conocida, pero dotada de una gran originalidad. Previamente, a modo de interludio, ofreceré algunas indicaciones acerca del desarrollo que experimenta la problemática vinculada la dimensión de la «corporalidad vivida propia», en la fenomenología de los años cuarenta en adelante. Por último, y a los efectos de hacer justicia - siquiera de modo simbólico-a los aportes de lo que he llamado la fenomenología avant la lettre, haré también una muy breve referencia, en un apéndice, a los casos de Aristóteles $\mathrm{y}$, sobre todo, de Goethe.

Naturalmente, la visión panorámica que ofreceré de este amplio y colorido paisaje distará mucho de ser exhaustiva y tendrá que renunciar necesariamente a abundar en el detalle. A su elaboración estará dedicado el resto de este trabajo. Sin embargo, antes de pasar a la consideración de las concepciones mencionadas, es preciso realizar algunas breves precisiones relativas a los rasgos más sobresalientes que caracterizan a las 
concepciones fenomenológicas de la percepción, en general, y del color, en particular. A los efectos que aquí interesan, conviene poner de relieve, al menos, dos rasgos fundamentales.

En primer lugar, y atendiendo a su orientación más general, puede decirse que las concepciones fenomenológicas se distinguen por poseer un carácter básicamente «no reduccionista» $\mathrm{o}$, incluso, decididamente «anti-reduccionista». En ellas se trata, ante todo, de dar cuenta del fenómeno del color, tal como éste se experimenta en la «percepción vivida». Vale decir: se trata de esclarecer las estructuras esenciales de la experiencia del color, en sus diversos posibles modos y variaciones, y ello atendiendo tanto al "contenido» de dicha experiencia como también a los «actos» $\mathrm{o}$, si se prefiere, los «modos de acceso» a través de los cuales tal contenido se ofrece ${ }^{1}$. Teorías constructivas basadas en estrategias de explicación reductiva por vía causal acerca del carácter meramente subjetivo o secundario de lo así experimentado, frente a otras propiedades de las cosas que poseerían un carácter más «objetivo» o más «básico», no juegan, al menos en principio, ningún papel relevante en el abordaje fenomenológico de la experiencia del color. Y ello, entre otras cosas, ya por el simple hecho de que, para poder ser acreditadas fenomenológicamente, tales teorías tendrían que fundarse ellas mismas en características propias del contenido de la experiencia a la que inevitablemente se refieren, incluso allí donde lo hacen para calificarla de meramente «subje-

\footnotetext{
${ }^{1}$ En la medida en que se apunta a estructuras esenciales de la experiencia del color, en general, los problemas vinculados con los criterios empíricos para la diferenciación de los colores, sus relaciones de compatibilidad o incompatibilidad, etc. no ocupan el centro del interés. Paradójicamente, son cuestiones de este tipo las que, en ocasiones, se suele abordar bajo el título de "fenomenología», en el marco de concepciones que carecen de toda genuina orientación fenomenológica. En tal sentido, véase la discusión, por lo demás, ampliamente documentada y altamente instructiva, en Hardin (1998) esp. cap. III: «Phenomenology and physiology».
} 
tiva». Así vistas las cosas, la tarea de una adecuada descripción fenomenológica de la experiencia misma del color posee, pues, un innegable primado metódico, frente a todo posible intento de explicación de corte reductivo. Como es obvio, esta orientación general de carácter «no reduccionista», o bien «anti-reduccionista», está en conexión inmediata con las premisas básicas del método fenomenológico y con algunas de las tesis metódicas más importantes compartidas por las diferentes concepciones de orientación fenomenológica. Tal es el caso, por ejemplo, de la tesis del primado metódico del mundo de la vida, como suelo último de la constitución de todo sentido, al que remiten en su origen también las estructuras objetivas que constituyen los objetos formales de las diferentes ciencias, incluida la ciencia matemática de la nauraleza².

Un segundo rasgo distintivo, estrechamente conectado con el anterior, concierne al carácter fuertemente «totalizador» $\mathrm{y}$ «contextualista» de las concepciones fenomenológicas por oposición al sesgo marcadamente «atomizante» que es propio de muchas de las concepciones de la percepción más representativas desde la Modernidad temprana hasta fines del siglo XIX, sobre todo, de aquellas dominantes en el ámbito de la tradición empirista. Así como en razón de su carácter «no reduccionista» no podrían orientarse básicamente a partir de la dis-

\footnotetext{
${ }^{2}$ Como es sabido, ésta es la posición elaborada expresamente por Husserl en su escrito sobre la crisis de las ciencias europeas, donde la temática vinculada con el «mundo de la vida» (Lebenswelt) irrumpe en el centro de la escena (véase Husserl 1936). Puesto que se trata de la última obra publicada en vida por Husserl, la cual, elaborada a lo largo de años, apareció finalmente en 1936, cuando el filósofo, que moriría en 1938, contaba ya con 76 años de edad, a menudo se ha querido ver en la temática vinculada con el «mundo de la vida» un desarrollo tardío del pensamiento husserliano. Pero tal suposición resulta infundada. Se trata, en realidad, de una temática que, si bien adquiere su despliegue específico y su papel protagónico en la obra de vejez, puede ser rastreada en sus orígenes hasta etapas bastante anteriores en la evolución filosófica de Husserl, y que entronca, además, de modo directo, con motivos centrales en el desarrollo de la filosofía alemana de la época. Para el origen y el alcance de la temática del «mundo de la vida» en Husserl, véase Orth 1999; 16-18, 107-144.
} 
tinción tradicional entre «cualidades primarias» y «cualidades secundarias», del mismo modo, las concepciones fenomenológicas de la percepción y del color tampoco podrían orientarse a partir de la noción de los así llamados sense data, tal como ésta es empleada en muchas teorías de la percepción situadas en la tradición empirista, desde Locke y Hume hasta Russell y Ayer, entre otros. De hecho, algunas de las concepciones fenomenológicas más representativas, como ocurre, por ejemplo, en el caso de Merleau-Ponty, polemizan de modo expreso con las concepciones alineadas en el así llamado «atomismo perceptivo», sea las de origen filosófico, o bien, las derivadas de la psicología empírica de fines del siglo XIX y comienzos del $x^{3}$. Por lo mismo, las concepciones fenomenológicas se oponen frontalmente a toda forma de «inferencialismo perceptivo» $\mathrm{O}$ de "constructivismo perceptivo», que pretenda dar cuenta de la percepción de las cosas y el mundo circundante en términos reductivos, como un tipo de percepción derivado, que se funda en la percepción de datos sensibles más básicos ${ }^{4}$.

Baste, por el momento, con esta caracterización general

\footnotetext{
${ }^{3}$ Véase Merleau-Ponty 1945; esp. 9-63. En este punto, Merleau-Ponty sigue la tendencia marcada por la «psicología de la forma», pero radicaliza sus consecuencias, a las que otorga un alcance ontológico. En tal sentido, véase la muy buena discusión de la polémica de Merleau-Ponty con el «atomismo perceptivo», en Dillon 1998; esp. cap. 4; quien enfatiza los aspectos ontológicos de la concepción de Merleau-Ponty.

${ }^{4}$ Esto no impide que, en el plano de la explicación genética, una teoría fenomenológica de la síntesis perceptiva, como la elaborada por Husserl en el período de la así llamada «fenomenología genética», pueda admitir la existencia de un nivel puramente pasivo de constitución, en el cual se tienen meros datos sensoriales, que no poseen todavía ninguna de las formas a las que pueden quedar elevados a través de los diferentes actos de aprehensión. En cualquier caso, tales «datos» no son jamás objetos percibidos. Como es sabido, sin embargo, la noción de «dato hylético» queda vinculada a una serie de tensiones presentes en el modelo husserliano de constitución, que dan cuenta, además, del progresivo desarrollo de dicho modelo, desde el período de la «fenomenología estática», en el cual la «materia sensorial» es tomada como privada de toda forma, al de la «fenomenología genética», en el cual se la concibe, más bien, como organizada en «campos sensoriales». Para una reconstrucción de aspectos centrales en el desarrollo de la concepción husserliana en torno a la conexión entre dato hylético y campo perceptivo, véase Rabanaque 1993.
} 
que adquirirá un sentido más pleno, espero, al cabo de la presentación de las concepciones elaboradas por los autores antes mencionados.

\section{W. Schapp: el color y su función exhibidora}

Wilhelm Schapp (1884-1965), jurista y filósofo, había estudiado filosofía primeramente con Rickert, en Friburgo, y con W. Dilthey y G. Simmel, en Berlín. Posteriormente, tras la conclusión de sus prácticas de derecho, estudió con Husserl en Gotinga, hacia donde se dirigió motivado por el interés en el pensamiento husserliano que despertó en él un seminario sobre Logische Untersuchungen, la obra fundacional de la fenomenología. En Gotinga, se doctoró en 1909 bajo la dirección de Husserl, con un estudio fenomenológico de la percepción publicado originalmente en 1910, el cual cuenta, con justa razón, como uno de los aportes más importantes a la investigación fenomenológica dentro de la producción de la primera generación de discípulos de Husserl ${ }^{5}$. En el período de postguerra, el pensamiento de Schapp experimenta un giro hacia la narratividad y «las historias» (plurale tantum), lo que concede a su fenomenología una nueva y muy original impronta. Pero tales desarrollos ya no guardan una relación directa con la temática que interesa aquít.

En su orientación general, la fenomenología de la percep-

\footnotetext{
${ }^{5}$ Véase Schapp 1910.

${ }^{6}$ Para un cuadro de conjunto del pensamiento de Schapp y su desarrollo, véase ahora los ensayos reunidos en Joisten (2010). En particular, para la «filosofía de las historias» desarrollada por Schapp en la fase tardía de su pensamiento, véase Eichler 2010, que analiza los aspectos ontológicos de la concepción de Schapp; y Greisch (2010), que la caracteriza en sus aspectos más generales y la sitúa por referencia al contexto de la fenomenología de postguerra, en particular, la francesa.
} 
ción elaborada por Schapp presenta de modo ejemplar los rasgos distintivos de los enfoques fenomenológicos antes mencionados. En particular, la concepción de Schapp tiene un sesgo decididamente anti-reduccionista. En tal sentido, Schapp subraya que el fenomenólogo debe dirigirse a la percepción "con mano leve» (mit leichter Hand) ${ }^{7}$, en una actitud caracterizada por una «entrega incondicionada» (unbedingte Hingabe), que apunta a lograr un «adentramiento en las cosas mismas» (Vertiefen in die Sachen selbst). El análisis debe ser realizado de modo tal que lo que se separa en él quede, a la vez, preservado tal como se $\mathrm{da}^{9}$, ya que sólo lo originariamente intuido pertenece propiamente al ámbito de la fenomenología ${ }^{10}$. La concepción elaborada por Schapp contiene, por otro lado, una cantidad de aspectos de detalle que ponen de manifiesto una notable capacidad para la práctica del análisis fenomenológico. Su punto de partida básico viene dado por la pregunta acerca de los medios a través de los cuales «se representa»o «se exhibe» (darstellt) el «mundo de las cosas» (Dingwelt) ${ }^{11}$. Lo que el análisis fenomenológico de la percepción busca poner de manifiesto son, piensa Schapp, los elementos que pertenecen de manera apriorística al modo en el que tiene lugar tal «representación» o «exhibición» (Darstellung) a través de cada uno de los sentidos y sus correspondientes correlatos objetivos. En la sección inicial y más general del tratamiento,

\footnotetext{
${ }^{7}$ Cf. Schapp 1910; 12.

${ }^{8}$ Cf. Schapp 1910; 13.

${ }^{9}$ Cf. Schapp 1910; 12.

${ }^{10}$ Cf. Schapp 1910; 14: «nur was geschaut ist, gehört in die Phänomenologie». Por lo mismo, Schapp critica severamente los intentos de explicación de lo originariamente dado por medio de teorías constructivas, como, por ejemplo, la teoría que asume que las cosas están constituidas de átomos: tal tipo de explicación nunca puede sustituir, sin más, el recurso a la experiencia vivida misma, y a la hora de practicar el análisis fenomenológico sólo puede ocasionar estorbo o desvío (cf. p. 19).

${ }^{11}$ Cf. Schapp 1910; 10-55.
} 
Schapp analiza el color como correlato de la visión ${ }^{12}$, el tono como correlato de la audición ${ }^{13}$ y el gusto ${ }^{14}$, para luego tematizar la relación entre los diferentes sentidos ${ }^{15} \mathrm{y}$, sobre esa base, la exhibición del espacio propio del «mundo de las cosas»" Dado que, como se dijo ya, todo el análisis está presidido por la intención de dar cuenta del modo en el que viene a la exhibición el «mundo de las cosas», el color adquiere una especial relevancia precisamente en razón de la peculiaridad de su función exhibidora. En la sección central de la obra, tal función exhibidora recibe, pues, un análisis mucho más pormenorizado ${ }^{17}$.

Pues bien, la fenomenología del color debe analizar el modo en el que vemos el mundo en condiciones de iluminación y claridad ${ }^{18}$. Lo que se nos ofrece primariamente por medio de la vista es «color» (Farbe), el cual es percibido por el ojo a través de las oscilaciones de la luz (Lichtschwingungen) ${ }^{19}$. El espacio, en cambio, no se ve, lo cual no quiere decir que se añada a la experiencia de los colores, por así decir, a través del pensamiento, sino que es también percibido, aunque de un modo peculiar, en concomitancia con los propios colores ${ }^{20}$. Por su parte, las cosas se nos aparecen meramente como complejos de colores y figuras, como figuras cubiertas o llenas de colores ${ }^{21}$. Pero la percepción de cosas y colores no es coextensiva, ya que aunque toda cosa se presenta como coloreada,

\footnotetext{
${ }^{12}$ Cf. Schapp 1910; 15-26.

${ }^{13}$ Cf. Schapp 1910; 26-32.

${ }^{14}$ Cf. Schapp 1910; 32-36.

${ }^{15}$ Cf. Schapp 1910; 37-42.

${ }^{16}$ Cf. Schapp 1910; 42-55.

${ }^{17}$ Cf. Schapp 1910; 57-128.

${ }^{18}$ Cf. Schapp 1910; 15.

${ }^{19}$ Cf. Schapp 1910; 17.

${ }^{20}$ Cf. Schapp 1910; 18.

${ }^{21}$ Cf. Schapp 1910; 18.
} 
el color no necesita estar asociado a una cosa: resulta posible imaginarse un mero mundo de colores o de sombras coloreadas ${ }^{22}$. Por otro lado, una cosa no se presenta nunca meramente como algo coloreado, sino como algo que posee muchas otras propiedades ( $v . g r$. dureza, solidez, peso, etc.). Lo que tenemos, pues, son cosas dotadas de propiedades, además de coloreadas y presentes en un mundo coloreado ${ }^{23}$. Al igual que el movimiento o la figura, el color contribuye a revelar, siquiera de modo indirecto, otras propiedades de las cosas a las que aparece asociado, tales como la textura, la elasticidad, etc. El color apunta, en tal sentido, a un cierto «interior de la cosa» (ein "Inneres" des Dinges) ${ }^{24}$. Piénsese, por ejemplo, en el color de metales como el oro y la plata y su particular brillo, que revela de modo indirecto la homogeneidad de esos materiales, por contraste con los colores opacos de la madera, conectados con su textura completamente diferente ${ }^{25}$.

Sobre esta base, Schapp elabora una diferenciada explicación del modo en el cual los colores contribuyen a la exhibición del «mundo de las cosas». Schapp pone de relieve el hecho de que el color sólo puede cumplir adecuadamente tal función de exhibición, si mantiene un cierto orden. Un elemento clave para entender este punto viene dado por lo que Schapp denomina la «claridad» o «nitidez» (Deutlichkeit) de la percepción. Ésta se da sólo bajo determinadas condiciones de cercanía e iluminación, pero se trata de condiciones habituales en el mundo de la vida cotidiana ${ }^{26}$. Ahora bien, no

\footnotetext{
${ }^{22}$ Cf. Schapp 1910; 18.

${ }^{23}$ Cf. Schapp 1910; 18.

${ }^{24}$ Cf. Schapp 1910; 20 s.

${ }^{25}$ Cf. Schapp 1910; 24.

${ }^{26}$ Cf. Schapp 1910; 58 ss. Schapp explica que, más allá de la existencia de ilusiones perceptivas y de la limitación de la zona de claridad perceptiva, la percepción misma no es responsable, como tal, de los mitos y las fantasías elaboradas en el mundo antiguo: éstas no tienen genuina
} 
sólo en el nivel de la escala perceptiva en el que se mueve la vida cotidiana hay un punto de claridad, sino que también lo hay tanto en el nivel microscópico como en el macroscópico, y quien usa un microscopio o bien un telescopio, respectivamente, sabe hallar dicho punto de claridad sin mayor dificul$\operatorname{tad}^{27}$. Así, no todo lo que es color exhibe, sin más, cosas, sino que sólo lo hace el color que posee un cierto orden, una cierta forma. Las condiciones contextuales bajo las cuales esto puede ocurrir son, como se dijo ya, la de suficiente cercanía y la de iluminación adecuada. Por su parte, el tipo peculiar de acto perceptivo que tiene por correlato objetivo la cosa, es el que Schapp denomina la "percepción observadora» (beobachtende Wahrnehmung) ${ }^{28}$. Como lo muestra de modo especialmente claro el uso del microscopio y el telescopio, hay, en cada caso, sólo una donación nítida de la cosa en la percepción observadora, mientras que todas las otras son más o menos imperfectas ${ }^{29}$.

En el caso concreto del color, la pregunta es, pues, cuándo, es decir, bajo qué condiciones tiene lugar el tipo específico de percepción de color que dotada de claridad o nitidez, haga posible, además, la exhibición de cosas. El ojo ve siempre color, incluso cuando está cerrado, pero esto mismo muestra que la percepción de color no siempre va asociada a la exhibición de cosas. Por otra parte, no cualquier color, por caso, el «color de lejanía» (Farbe der Entferntheit), por contraste con

base fenoménica en la percepción misma. Por otra parte, explica Schapp que la percepción por sí sola nunca engaña, ya que tampoco exige que se confíe, sin más, en ella. El que percibe tiene conciencia concomitante de las condiciones favorables o desfavorables en las que se da la percepción. Así, por ejemplo, lo lejano se percibe como lejano. En tal sentido, la percepción no nos engaña, sino que en ocasiones, a lo sumo, nos deja en la estacada (cf. p. 63 s.).

${ }^{27}$ Cf. Schapp 1910; 61 ss.

${ }^{28}$ Cf. Schapp 1910; 69 ss.

${ }^{29}$ Cf. Schapp 1910; 71 ss. 
el «color de cercanía» (Farbe der Nähe); ni tampoco cualquier combinación de colores está en condiciones de exhibir cosas: hay que atender aquí a un conjunto de leyes apriorísticas (apriorische Gesetze) que rigen la función de exhibición de cosas a través del color, las cuales están fundadas en la esencia (Wesen) de la percepción ${ }^{30}$. Y ello con referencia a dos aspectos diferentes: por un lado, la «escala de los colores» (Farbenskala), que da cuenta de la diferencia cualitativa entre los diversos colores; por otra, los «efectos lumínicos» (Beleuchtungseffekte) conectados con las «configuraciones lumínicas» (Lichtgebilde), que dan cuenta de distinciones tan importantes como la de «color de cercanía» y «color de lejanía», etcétera $^{31}$. En la percepción ingenua, que incluye aquí tanto la del hombre común como la del cientifico, el ver va dirigido a la cosa coloreada, atravesando, por así decir, las «configuraciones lumínicas», pero sin reparar de modo directo en ellas, al menos, cuando las condiciones contextuales y el carácter de los «efectos lumínicos» son más o menos normales. El pintor, en cambio, atiende de modo directo a las «condiciones lumínicas» que busca reproducir sobre la tela, ya que se vale de ellas para representar cosas. Las convierte así, en cierto modo, en objetos de percepción. Pero esto mismo muestra ya que dichas «configuraciones lumínicas» contribuyen de modo decisivo a la exhibición de cosas. Y, por lo mismo, el fenomenólogo debe intentar analizar su peculiar función exhibidora, que es algo mucho más difícil que el mero fijar la atención perceptiva sobre los reflejos, manchas, sombras coloreadas, etcétera ${ }^{32}$. Con todo, lo que el contraste entre la actitud perceptiva ingenua

\footnotetext{
${ }^{30}$ Cf. Schapp 1910; 77.

${ }^{31}$ Cf. Schapp 1910; 77 s.

${ }^{32}$ Cf. Schapp 1910; 79 ss.
} 
y la actitud perceptiva del pintor pone de manifiesto es el hecho, de fundamental importancia, de que los «efectos lumínicos» y las correspondientes «configuraciones lumínicas» cumplen su peculiar función exhibidora de cosas sustrayéndose ellos mismos a la captación temática: cuanto más aguda y focalizada sobre la cosa es la observación perceptiva, tanto más desaparecen del primer plano los «efectos lumínicos» y las «configuraciones lumínicas», al punto de no jugar ya papel alguno en el caso de la observación a través de microscopio ${ }^{33}$.

Desde el punto de vista de la fenomenología de la percepción, la distinción más importante es aquí, por tanto, la distinción entre el color constante a través de los diversos cambios de condiciones de iluminación, lo que Schapp denomina el «color adherente» (anhaftende Farbe), por un lado, y los «efectos lumínicos» que se corresponden con las «configuraciones lumínicas», por el otro ${ }^{34}$. Ahora bien, entre las «configuraciones lumínicas» hay algunas que contribuyen a la exhibición de la cosa, y otras que no. Así, por ejemplo, la iluminación que cae sobre algunos de los lados de un objeto cumple una función exhibidora, mientras que la sombra que cubre los lados no iluminados, no. Cuando se trata de observar la cosa, como tal, las "configuraciones lumínicas» que no contribuyen a su exhibición resultan, por así decir, «tachadas» o «canceladas» (durchstrichen). Así, por ejemplo, en el caso de un objeto sólo parcialmente iluminado, la mirada busca el lugar preciso en el cual puede alcanzar perceptivamente el carácter propio de la cosa ${ }^{35}$. Los lugares que no contribuyen directamente a ello son, sin embargo, necesarios

\footnotetext{
${ }^{33}$ Cf. Schapp 1910; 81 s.

${ }^{34}$ Cf. Schapp 1910; 83.

${ }^{35}$ Cf. Schapp 1910; 83 ss.
} 
como partes integrantes de la percepción total, dentro de la cual funcionan en calidad de «trozos vacíos» (Leerstücke) ${ }^{36}$. Cada «configuración lumínica» puede cumplir o no una función de exhibición, según sean el objeto y el contexto perceptivo. Pero el papel decisivo que las «configuraciones lumínicas» cumplen, en general, en la exhibición de cosas se pone de manifiesto a través del hecho de que su ausencia o falta de variedad impide que el «color adherente» permita la exhibición: en el caso de objetos alejados es precisamente la falta de las variaciones cromáticas asociadas a las «configuraciones lumínicas» lo que produce que el «color adherente», en su uniformidad sin relieves, ya no pueda exhibir la cosa, pues sólo la composición de color puede exhibir, mientras que la absoluta uniformidad cromática carece de genuino potencial exhibidor ${ }^{37}$. Por su parte, el «color adherente» nunca se da en estado puro, sino siempre cubierto de «efectos lumínicos», de modo tal que nunca se da, sin más, de modo directo, aunque se muestra en mayor o menor medida según los casos. Como quiera que sea, el hecho de que el «color adherente» se presente como inmóvil e invariante, mientras que los «efectos lumínicos» son móviles y variables, permite distinguirlos sin que se confundan. Así, por ejemplo, no hay confusión insalvable entre el color oscuro de un objeto y la sombra que se proyecta sobre él, ni entre el blanco de un objeto y la luz que cae sobre él ${ }^{38}$. Hay, pues, una distinción irreductible de carácter formal-categorial entre el «color adherente», por un lado, y los «efectos lumínicos» y las «configuraciones lumínicas», por el otro: el primero presenta una configuración uní-

\footnotetext{
${ }^{36}$ Cf. Schapp 1910; 85.

${ }^{37}$ Cf. Schapp 2010; 86 s.

${ }^{38}$ Cf. Schapp 2010; 87 ss.
} 
vocamente determinada, mientras que los últimos carecen de univocidad, precisamente, por ser reconfigurables ${ }^{39}$. El «color adherente» provee, explica Schapp, el «medio» (Medium) que nos permite trascender las meras «configuraciones lumínicas» en dirección de los objetos ${ }^{40}$. El «color adherente» no es él mismo algo cósico, pero aparece estrechamente vinculado con las cosas y revela, en cierto modo, su interior: lo muestra, por así decir, en la superficie ${ }^{41}$.

Como se advierte, la posición elaborada por Schapp combina dos aspectos complementarios: por una parte, enfatiza el papel decisivo que desempeñan las «configuraciones lumínicas» en la exhibición de cosas; por otra, pone de relieve el hecho de que es el «color adherente», y no las «configuraciones lumínicas» lo que exhibe de modo directo la cosa, a la que queda inmediatamente vinculado. El resultado es, pues, que sólo puede haber exhibición de cosas, cuando se da una adecuada constelación de «color adherente» $\mathrm{y}$ «configuraciones lumínicas». Pero tales constelaciones responden a una cierta legalidad, en la cual juega un papel primordial la prioridad del «color adherente» como medio de exhibición de la cosa. Así, ya en el plano de la experiencia perceptiva ingenua se distingue entre la genuina percepción de la cosa, por un lado, y lo que sería una mera aparición fenoménica, en el sentido vulgar (pre-fenomenológico) de la expresión, por el otro. Y tal distinción se establece con arreglo a la diferencia categorial entre el «color adherente» y las «configuraciones lumínicas». Más allá de posibles engaños transitorios, al menos, en el ámbito de claridad y nitidez propio de la percep-

\footnotetext{
${ }^{39}$ Cf. Schapp 2010; 89.

${ }^{40}$ Cf. Schapp 2010; 90.

${ }^{41}$ Cf. Schapp 2010; 92.
} 
ción observante, los meros «efectos lumínicos» no pueden adquirir de modo duradero la forma del «color adherente», que es la propia de un color recluido en la figura misma del objeto. Esta fijeza de la forma del «color adherente» es lo que da cuenta de su prioridad, como medio de exhibición de la cosa misma ${ }^{42}$. El «color adherente» hereda, en cierto modo, el carácter determinado (Bestimmtheit) que posee la figura del objeto, y adquiere así un tipo peculiar de existencia (Sonderexistenz), que lo distingue de todos aquellos colores que no aparecen vinculados del mismo modo a esa misma cosa. Es aquí donde reside el fundamento de legitimidad (Rechtsgrund) para la distinción entre lo que cuenta como una buena o una mala percepción de la $\operatorname{cosa}^{43}$. La prioridad del «color adherente» funda, pues, un cierto «orden cromático» (Farbenordnung), que guarda una relación estructural con el modo en que se nos presenta el «mundo de las cosas», justamente, en la medida en que la "exhibición de cosas» (Dingdarstellung) mantiene una relación de dependencia respecto de dicho «orden cromático» ${ }^{44}$. Schapp ilustra tal dependencia por medio del recurso al caso de determinadas «ilusiones perceptivas» (v. gr. un objeto que primero se confunde con una sombra presente en un segundo objeto, para luego ser identificado como un objeto diferente del primero, etc.). El reconocimiento de tales ilusiones como meras ilusiones trae consigo también, y necesariamente, una reconfiguración del correspondiente "orden cromático», de modo tal de adecuar la distribución del esquema basado en la distinción categorial entre «color adherente»y «efectos lumínicos» a lo que en

\footnotetext{
${ }^{42}$ Cf. Schapp 2010; 94 ss.

${ }^{43}$ Cf. Schapp 2010; 96 s.

${ }^{44}$ Cf. Schapp 2010; 98.
} 
cada caso reclama el nuevo modo de identificar y distinguir los objetos presentes dentro del campo perceptivo ${ }^{45}$.

En suma: el «orden cromático» debe ser considerado, al mismo tiempo, como un «orden de exhibición» desde el punto de vista de la cosa exhibida, y como un «orden de percepción» desde el punto de vista del sujeto de la experiencia ${ }^{46}$. Aquí impera una legalidad que da cuenta de la complejidad subyacente a las formas más elementales de la experiencia perceptiva. Todo lo percibido visualmente es color. Y en la medida en que está al servicio de la percepción, el color apunta a la exhibición de cosas. Pero, para poder exhibir cosas, el color debe ordenarse, articularse y adquirir una determinada forma, y ello de modo tal que a toda exhibición de cosas le pertenece tanto «color adherente» como «efectos lumínicos», que dan origen a las correspondientes «configuraciones lumínicas». A la estructura interna de tal tipo de experiencia pertenece el hecho de que sólo una parte de ella, la que corresponde al «color adherente» vinculado con la cosa, es «percibida» (wahrgenommen), mientras que la otra, la que se corresponde con las «configuraciones lumínicas», debe ser «sentida» (empfunden), pero sin ser transformada ella misma en objeto de percepción, pues es a través de su propia cancelación perceptiva como realiza su propio aporte al logro del «fin» de la percepción, que, en definitiva, no es otro, según Schapp, que el de la exhibición de $\cos ^{4}{ }^{47}$.

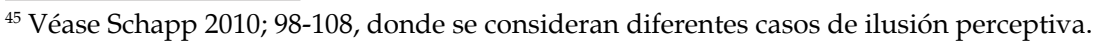

${ }^{46}$ Cf. Schapp 2010; 108.

${ }^{47}$ Cf. Schapp 2010; 114 ss.
} 


\section{A. Reinach: los posibles modos de concebir el color}

Adolf Reinach (1883-1917), el notable discípulo de Husserl caído en combate poco antes de cumplir 34 años, no pudo dejar como legado una obra extensa, pero la indiscutible calidad de sus principales trabajos permite situarlo como un fenomenólogo de primer rango, que se cuenta, sin duda alguna, entre los más talentosos de su generación. Reinach no elaboró una fenomenología de la percepción al estilo de la de Schapp. Sus principales investigaciones están dedicadas, más bien, a problemas centrales del ámbito de la filosofía del derecho, la filosofía de la lógica y la filosofía de las matemáticas, así como también a la reflexión sobre los fundamentos de la fenomenología y la filosofía en general. En la excelente edición crítica de las obras de Reinach realizada por Karl Schuhmann y Barry Smith, que comprende tanto las obras publicadas como las inéditas, se incluye, sin embargo, una escueta reflexión de sólo tres páginas dedicada a la problemática del color que data del año $1913^{48}$. El texto resulta de interés por diversos motivos y vale la pena comentar brevemente su origen y su contenido.

Como indican los editores, la reflexión sobre el color tiene su origen en el coloquio filosófico del semestre de verano de 1913, en el cual Reinach discutió con sus estudiantes avanzados la concepción husserliana de la percepción, según la cual la cosa se muestra en el flujo de las impresiones sensibles. En ese marco general, y ante la pregunta acerca de cómo se manifiestan las cosas, la discusión derivó hacia la

${ }^{48}$ Cf. Reinach 1913. 
doctrina de las cualidades primarias y secundarias, y hacia la cuestión de cómo se manifiestan el color, la luz, la iluminación, etcétera ${ }^{49}$. El texto discute tres posibles modos de concebir la relación que mantiene el color con los objetos. La primera de ellas es la que asume que los objetos corpóreos del mundo poseen colores propios, los cuales pueden ser percibidos en condiciones adecuadas de iluminación ${ }^{50}$. La segunda concepción sostiene, en cambio, que en condiciones de completa claridad los cuerpos son incoloros y, por tanto, invisibles. Los colores serían, pues, meras funciones de las radiaciones que se reflejan de modo difuso. Todo color sería mera coloración pasajera, vinculada a determinadas condiciones de iluminación. Así, por ejemplo, afirmar que una cosa es «blanca», aunque ahora presenta otra coloración, querría decir, en realidad, que esa cosa es «blanca», bajo luz blanca. El primado de la luz blanca, como aquella que define lo que se considera el verdadero color de la cosa, poseería un carácter meramente práctico o convencional. Sin embargo, según este modo de ver, el color ocuparía, de todos modos, un lugar preeminente entre las cualidades secundarias en la medida en que poseería un carácter presentativo que remite a algo diferente, cosa que no ocurre, por ejemplo, con el calor. Ahora bien, mientras que la concepción anterior podría considerarse viable, esta segunda presentaría, a juicio de Reinach, la dificultad de que no permite realmente hacer justicia a la distinción fenoménica entre el genuino color de algo y su mera coloración pasajera ${ }^{51}$. Por último, la tercera concepción asume el carácter meramente subjetivo de las

\footnotetext{
${ }^{49}$ Cf. Schuhmann - Smith 1989 II; 737.

${ }^{50}$ Cf. Reinach $1913 ; 365$.

${ }^{51}$ Cf. Reinach 1913; 365 s.
} 
impresiones de color: los colores serían «mera apariencia» (bloße Erscheinung), en la medida en que ya no se admite ninguna conexión causal entre el color y las propiedades que objetivamente poseerían las $\operatorname{cosas}^{52}$. Reinach considera, en particular, aquellas variantes específicamente filosóficas de esta posición, que sostienen o bien que la materia no puede ser coloreada (así, H. Lotze), o bien que asumir la existencia de cualidades objetivas, tales como los colores, conduciría a contradicciones insalvables (así, F. Brentano, por un lado, y H. Cohen y P. Natorp, que siguen la línea argumentativa inaugurada por Locke, por el otro). Por su parte, Reinach replica que la física moderna no ha mostrado la imposibilidad de que las cosas posean color, y que los argumentos filosóficos destinados a probarla son meramente constructivos y carecen de base fenomenológica ${ }^{53}$.

Sobre esta base, Reinach manifiesta su preferencia por argumentaciones de carácter más marcadamente fenomenológico, como la ofrecida por Julius Bergmann, que pone de relieve el hecho de que las cualidades sensibles, tales como colores, olores, etc., incluyen necesariamente la referencia a su ser percibidas en general, aunque no a tales o cuales sujetos concretos que efectivamente las perciben. Con todo, la fenomenología de las cualidades sensibles desarrollada por Bergmann es, a juicio de Reinach, insuficiente, entre otras cosas porque no hace justicia a la peculiar función de donación (gebende Funktion) que cumplen los colores, incluso allí donde no se pueda hablar realmente de «color objetivo» (objektive Farbe) ${ }^{54}$. Reinach enfatiza este aspecto a través de

\footnotetext{
${ }^{52}$ Cf. Reinach $1913 ; 366$.

${ }^{53}$ Cf. Reinach 1913; 366 s.

${ }^{54}$ Cf. Reinach 1913; 367.
} 
una comparación con Kant: así como Kant ve en el espacio una forma de la intuición de las cosas, algo análogo podría decirse de la coloración (Farbigkeit): el color posee algo que nos remite a las cosas (etwas uns an [die] Dinge Hinweisendes). Y ello es así, aun cuando el color mismo no pueda ser visto como algo cósico, pues tampoco toma parte de lo que le ocurre mecánicamente a la cosa: el color, como tal, no se quema, no se rompe, no se humedece, etc., sino que sólo lo hace, en cada caso, la cosa misma que posee color ${ }^{55}$.

\section{Aportes de la psicología}

La estrecha vinculación que, ya en razón de su misma deuda de origen para con el pensamiento de Brentano, mantuvo la fenomenología husserliana con algunas de las principales corrientes de la psicología alemana de la primera mitad del siglo $x x$ es bien conocida ${ }^{56}$. Por un lado, la propia fenomenología dio lugar, ya en tiempos de la primera generación de seguidores de Husserl, a sustanciosas investigaciones destinadas a esclarecer fenómenos y estructuras fundamentales del ámbito de lo psíquico. Además de los aportes realizados por el propio Husserl a lo que él mismo concebía como una "psicología fenomenológica» ${ }^{57}$, hay que mencionar aquí, muy especialmente, los importantes trabajos de Alexander Pfänder (18701941), que tuvieron un considerable eco en el ámbito de la psicología y la psiquiatría ${ }^{58}$. Por otro lado, desarrollos teóri-

\footnotetext{
$\overline{{ }^{55} \text { Cf. Reinach } 1913 ; 367 .}$

${ }^{56}$ Para una presentación sintética de las vinculaciones de la fenomenología con el desarrollo de la psicología en el siglo xx, véase Waldenfelds 1992; 84 ss.

${ }^{57}$ Véase esp. Husserl 1925.

${ }^{58}$ Véase Pfänder 1900, 1904, 1913, 1916 y 1933. Para una presentación de conjunto de la in-
} 
cos producidos en el interior de la propia psicología mostraron muy pronto su potencial de convergencia con la nueva manera de abordar el ámbito de lo psíquico inaugurada por la fenomenología. En particular, la llamada «psicología de la forma» (Gestaltpsychologie), con su fuerte oposición a toda variante del atomismo perceptivo y su orientación de carácter decididamente totalizador y contextualista, presenta, en aspectos importantes, una estrecha afinidad con las posiciones más distintivas elaboradas en el seno de la escuela fenomenológica, sobre todo, a la hora de dar cuenta de problemas centrales en el ámbito de la teoría de la percepción y la teoría de la conciencia ${ }^{59}$. En particular, hay que mencionar el caso de los principales representantes de la primera generación de llamada «escuela berlinesa», tales como Carl Stumpf (1848-1936), Max Wertheimer (1880-1943), el genuino fundador de la escuela, Adhemar Gelb (1887-1936), Kurt Goldstein (1878-1965), Wolfgang Köhler (1887-1967) y Kurt Koffka (1886-1941), entre otros, a los cuales puede añadirse, como representante principal de la segunda generación de la escuela, Wolfgang Metzger (1899-1979). Por otro lado, hay que

\footnotetext{
fluencia de Pfänder en el ámbito de la psicología y, especialmente, de la psiquiatría, véase Kuhn 1982.

${ }^{59}$ Desde luego, esta afirmación no pretende sugerir la existencia de una completa congruencia entre el proyecto teórico de la fenomenología, por un lado, y el de la Gestaltpsychologie, por el otro, al modo en que, en su día, Merleau-Ponty había sugerido que la última practicó un tipo peculiar de reflexión para el cual la primera proveyó la correspondiente base teórica (véase Merleau-Ponty 1945; 62, n. 1). Esta asimilación que, de modo indirecto, degrada a la Gestaltpsychologie al nivel de una práctica carente de una genuina base teórica propia, resulta poco menos que insostenible. Más bien, la afinidad entre ambas escuelas concierne a la orientación de los análisis de fenómenos particulares vinculados con la percepción y la conciencia, y no a una misma orientación en el plano teórico o metateórico. A este respecto, véase la severa crítica de la posición de Merleau-Ponty elaborada por Toccafondi (2003; esp. 147 ss.), de quien tomo también la cita anterior. Para una presentación de conjunto del desarrollo de la Gestaltpsychologie en la cultura alemana entre 1890 y 1967, véase Ash 1995. Una concisa y muy útil exposición de conjunto del desarrollo de la psicología del color, desde los orígenes en el s. XIX hasta la actualidad, véase Gilchrist 2006.
} 
mencionar aquí también los nombres de David Katz (18841953), quien desde los tiempos de realización de su tesis doctoral en Gotinga mantuvo estrecho contacto con Husserl y llevó a cabo posteriormente importantes contribuciones a la psicología de la percepción, a través de las cuales entró en contacto también con la «psicología de la forma»; y de Karl Bühler (1879-1963), uno de los principales representantes de la «psicología del pensamiento» (Denkpsychologie) de la Escuela de Würzburg, corriente emparentada con la «psicología de la forma». Siendo muy amplia la gama de temas comunes que permiten establecer lazos entre ambas escuelas, en lo que concierne específicamente a la problemática vinculada con la percepción del color, hay que hacer referencia aquí, siquiera de modo muy selectivo, a los aportes realizados por Katz, Gelb, Koffka y Bühler. Previamente, conviene, sin embargo, hacer también una breve referencia a la influyente obra de Ewald Hering (1834-1918), por más que éste no fuera un seguidor de la escuela fenomenológica ni tampoco un representante de la «psicología de la forma».
a) E. Hering

Ewald Hering, afamado fisiólogo de Leipzig, realizó, entre otras cosas, una importante investigación sobre la percepción lumínica basada fuertemente en novedosos métodos experimentales, lo que lo condujo a desarrollar una teoría del color y la percepción del color opuesta a las concepciones puramente fisicalistas y mecanicistas en la línea de la elaborada por Hermann von Helmholtz ${ }^{60}$. Desde el punto de

${ }^{60}$ Cf. Hering 1905. 
vista que aquí interesa, el principal aporte de Hering se vincula con la discusión en torno al fenómeno de la «constancia cromática» (Konstanz der Farben, Farbenkonstanz), el cual juega un papel central en las posteriores concepciones fenomenológicas. Se trata del hecho de que las cosas visibles del mundo se nos aparecen con un color relativamente constante, a pesar de las variaciones de luminosidad que se registran en el transcurso del día o, en general, bajo condiciones de iluminación diferentes (p. ej. las de un día soleado y las de un día nublado) ${ }^{61}$. Hering consideraba que el fenómeno de la "constancia cromática» constituye uno de los hechos más curiosos y más importantes en el ámbito de la óptica fisiológica, y llamó la atención sobre su papel decisivo a la hora de dar cuenta de la distinción fenoménica entre el color propio de una cosa y la coloración que puede adquirir transitoriamente bajo condiciones diferentes de iluminación. Un mundo sin relativa "constancia cromática», sería un mundo en el cual, por caso, un trozo de tiza tendría que presentar, en un día nublado, un color semejante al que presentaría un trozo de carbón en un día de sol $^{62}$. Se trata pues de una condición fenoménica fundamental a la hora de dar cuenta de la diferencia formal-categorial entre el color propio de una cosa y la coloración pasajera que puede adquirir bajo diversas condiciones de iluminación, un aspecto que, como se vio, juega un papel central también en la concepción de Schapp. Por su parte, Hering intentó proveer una explicación del fenómeno de la «constancia cromática» dotada de un fun-

\footnotetext{
${ }^{61}$ Para el fenómeno de la relativa "constancia cromática», en general, véase ahora las discusiones en Hardin 1998; 82 ss., y Ebner 2007, quienes, tanto en el plano metódico como en el ontológico, parten, sin embargo, de asunciones básicas fuertemente divergentes de aquellas que caracterizan a las posiciones fenomenológicas más representativas.

${ }^{62}$ Hering 1905; § 6, 16.
} 
damento de carácter fisiológico y organicista, que no podía quedar reducido, sin embargo, a la mera interacción mecánica con el medio. Así, partiendo de un modelo generalizado de interacción entre la retina y el campo visual total, Hering sostuvo que la "constancia cromática» debía explicarse, en definitiva, por referencia a dos factores concurrentes: por un lado, la limitación del rango lumínico y cromático que somos capaces de percibir; por otro, la función compensatoria de las variaciones lumínicas y estabilizadora del color que desempeñan las anteriores trazas de experiencia cromática y lumínica. Con ocasión de nueva activación, estas últimas dan lugar a la intervención de lo que Hering denomina «colores memorizados» (Gedächtnisfarben): los colores estabilizados y constantes que fijamente quedan asociados a las $\operatorname{cosas}^{63}$.

b) D. Katz

Considerada en sus aspectos de detalle, la explicación ofrecida por Hering presenta diversos problemas de contenido y también de consistencia interna, en los cuales no puedo deternerme aquí6 ${ }^{4}$. Desde el punto de vista que aquí interesa, baste simplemente con señalar que Hering opera con una visión poco menos que indiferenciada del fenómeno de la "constancia cromática», en la cual no juega un papel relevante la referencia a los diversos modos posibles de presentación del color. Y es aquí, precisamente, donde se inserta el decisivo aporte de David Katz. En su escrito de habilitación, del

\footnotetext{
${ }^{63}$ Cf. Hering 1905; § 6, 17 ss.

${ }^{64}$ Para una discusión crítica, véase Rang 1990; 184-199, donde la posición de Hering es discutida, junto con la de Helmholz y Katz, en el marco del análisis de los presupuestos de la concepción husserliana de los «escorzos» (Abschattungen) perceptivos.
} 
cual Husserl fue uno de los evaluadores académicos, Katz elaboró una investigación dedicada a la percepción del color que ha gozado, hasta tiempos recientes, de amplia consideración. El trabajo fue publicado por primera vez en 1911 y reeditado, con amplias reelaboraciones y nuevo título, en $1930^{65}$. La principal diferencia de enfoque entre ambas versiones viene dada por el carácter más marcadamente teórico de la segunda versión que la aproxima fuertemente al tipo de consideración propio de la "psicología de la forma», frente al carácter fuertemente empírico y, en cierto modo, reacio a la teorización de la primera. En cualquier caso, habían sido precisamente los resultados experimentales presentados en la primera edición los que habían motivado el interés de representantes de la «psicología de la forma». Por otra parte, la estrecha vinculación de Katz, al menos, en la fase más avanzada de su producción, con el pensamiento husserliano y su cercanía al método fenomenológico resultan manifiestas $\mathrm{y}$ han sido puestas de relieve en muchas ocasiones ${ }^{66}$.

Pues bien, a través de un conjunto de nuevos experimentos que profundizaban en la línea abierta por Hering, Katz logró ampliar de modo considerable la base fenoménica disponible para la discusión del problema, lo cual le permitió introducir, además, una diferenciación tipológica y conceptual sustancialmente mayor. Más concretamente, Katz distinguió una serie de diversos modos de manifestación del color en el espacio, tales como el «color de superficie»(Oberflächenfarbe),

\footnotetext{
${ }^{65}$ Katz 1911 y 1930. A esta famosa investigación sobre el color se añade también la que Katz dedicó a la percepción del tacto. Véase Katz 1925.

${ }^{66}$ En particular, véase Spiegelberg 1972; 42-52, quien provee una discusión detallada de los diferentes aspectos de la vinculación de Katz con la fenomenología. Para una sucinta exposición de conjunto de la posición de Katz en el campo de la experiencia visual y cromática, véase Gilchrist 2006; 26-40, quien da cuenta, además, de los ingeniosos métodos experimentales empleados por Katz.
} 
que se corresponde con el color que aparece en la superficie de los objetos; el "color de área» o "color fílmico» (Flächenfarbe), que carece de localización y caracteres espaciales definidos (v. gr. una porción de cielo azul en un día nublado); el «color espacial» o «color de volumen» (Raumfarbe), que es el color transparente que llena un volumen en sus tres dimensiones, tal como ocurre en el caso los líquidos transparentes coloreados; el «color luminoso» (leuchtende Farbe); el «brillo» o «lustre» (Glanz), etc. ${ }^{67}$ Todos estos modos de manifestación expresan la inherente espacialidad del color —uno de los aspectos centrales puestos de relieve por Katz-, en la medida en que el color siempre se presenta bajo la forma de alguna de sus posibles configuraciones espaciales. El reconocimiento de esta pluralidad de modos de manifestación trae aparejada, al mismo tiempo, una ampliación del ámbito de consideración de los aspectos vinculados con el fenómeno de la «constancia cromática». Sin embargo, Katz no adopta aquí la posición más elemental, que consistiría en sostener que un mismo color se presenta en todos los diferentes modos de manifestación. Por el contrario, como señala acertadamente Spiegelberg, Katz parece pensar, más bien, que las diferencias entre los principales modos de manifestación, por ejemplo, entre «color de superficie» y «color de área», afectan la identidad misma del color en cuestión, de modo tal que ya no se trata del «mismo» color, sino de diferentes tipos de color, en diferentes contextos de aparición, aunque éstos posean, en definitiva, un sustrato material común ${ }^{68}$. Por lo mismo, Spiegelberg sugiere hablar aquí de algo así como diferentes

\footnotetext{
${ }^{67}$ Cf. Katz 1930; esp. §§ 1-9.

${ }^{68}$ Cf. Spiegelberg 1972; 47.
} 
«encarnaciones» (incarnations) de un mismo color ${ }^{69}$. Por otra parte, el trabajo experimental de Katz le permitió reconocer que el fenómeno de la «constancia cromática» implica que no sólo debe ser percibida la cualidad del color, sino también su «luminosidad» o «iluminación» (Beleuchtung), como la llama Katz, y su «grado de saturación» (Ausgeprägtheit) ${ }^{70}$. En último término, puede decirse entonces que el fenómeno de la relativa «constancia cromática» involucra, de uno u otro modo, la configuración total del correspondiente campo visual.

\section{c) A. Gelb}

Importantes contribuciones empíricas y teóricas a la discusión de los problemas vinculados con el fenómeno de la relativa «constancia cromática» realizó también Adhemar Gelb, creativo filósofo y psicólogo de origen ruso, que desarrolló la mayor parte de su actividad de investigación en Frankfurt (1912-1931), donde colaboró estrechamente con Kurt Goldstein (1878-1965), y en Halle (1931-1933), donde fue Profesor Ordinario y Director del Seminario de Psicología (1931). En un muy influyente artículo publicado en $1929^{71}$, Gelb presentó de modo ordenado sus resultados, los cuales resultaban, en general, ampliamente coincidentes con los alcanzados por Katz, como éste mismo reconoce en la versión reelaborada de su propia concepción. En efecto, también Gelb enfatizaba decididamente el componente totalizador y contextual de la percepción visual, al cual no se puede hacer debida jus-

\footnotetext{
${ }^{69}$ Cf. Spiegelberg 1972; 7 . Para la diferencia entre «materia cromática» (Farbmaterie) o «valor cromático» (Farbwert) y «modo de manifestación» (Erscheinungsweise), véase Katz 1930; § 8.

${ }^{70}$ Cf. Katz 1930; §§ 13-40.

${ }^{71}$ Cf. Gelb 1929.
} 
ticia por medio del recurso a un simple esquema «estímulorespuesta», al modo de los modelos explicativos de orientación atomista o elementarizante: sólo por referencia al campo visual total, con su peculiar configuración cromática y espacial, se puede dar cuenta de la experiencia de nuestro mundo visual y también de la posibilidad de una cantidad de fenómenos peculiares, como los relacionados con la «constancia cromática ${ }^{72}$. Entre los muchos experimentos ingeniosos de Gelb, se ha hecho famoso el que apunta a responder la pregunta de por qué la luna se ve blanca durante la noche. Gelb colocó un trozo circular de papel negro, que representa la luna, bajo la luz de un proyector, que representa el sol, en una habitación oscura, que hace las veces del espacio exterior. En tales condiciones, el papel negro se ve blanco, pero si se le coloca por detrás una hoja de papel blanca, entonces el círculo de papel negro vuelve a verse negro. Así, Gelb pudo mostrar que la iluminación más intensa dentro de un determinado escenario visual aparece como blanca, una constatación que ha sido confirmada por la experimentación posterior ${ }^{73}$. Se trata, obviamente, de un resultado que confirma, además, la decisiva importancia que posee la configuración del campo visual total en la percepción del color.

d) K. Koffka

Kurt Koffka se doctoró en Berlín en 1909 bajo la dirección de Carl Stumpf, trabajó en Frankfurt con Max Wertheimer y posteriormente fue profesor en Giesen entre 1911 y 1927. Koffka fue el principal responsable de la difusión y el esta-

\footnotetext{
${ }^{72}$ Cf. Gelb 1929; 673.

${ }^{73}$ Cf. Bressan 2005.
} 
blecimiento de la "psicología de la forma» en EEUU, hacia donde, tras previas visitas en 1924 y 1925, emigró en 1927, para trabajar en el Smith College de Northampton, Massachusetts, donde permaneció hasta su muerte en 1941. Además de ser un notable sistematizador y difusor de la posición de la "psicología de la forma», Koffka realizó también aportes específicos de importancia. Por lo demás, Koffka asumió sin mayores reservas su cercanía al método fenomenológico, a cuya discusión dedicó una breve sección de su importante y muy difundida obra sobre los fundamentos de la "psicología de la forma», publicada originalmente en inglés ${ }^{74}$. De especial interés son los aportes de Koffka en el campo de la psicología de la percepción ${ }^{75}$. Ya desde sus primeros trabajos, Koffka atacó decididamente la concepción asociacionista tradicional, poniendo en duda sus fundamentos básicos, particularmente la adopción, como punto de partida, de un dualismo irreductible entre estímulo y sensación, por un lado, y la asunción según la cual la sensación sería una mera función del estímulo, vale decir, lo que Köhler denominó la «suposición de constancia» $\mathrm{O}$ «hipótesis de constancia» (Konstanzannahme), por el otro ${ }^{76}$.

En lo que concierne de modo más específico a la percepción visual y la experiencia del color, hay que mencionar aquí la contribución de Koffka a la discusión de los problemas vinculados con el fenómeno de la "constancia cromática»" ${ }^{77}$. Aquí Koffka parte de la asunción, compartida con Katz y Gelb, según la cual los fenómenos de «constancia cromática» y trans-

\footnotetext{
${ }^{74}$ Cf. Koffka 1935; 73 ss.

${ }^{75}$ Cf. Koffka 1924.

${ }^{76}$ Cf. Koffka 1924; 534 et passim; véase también Koffka 1925.

${ }^{77}$ Cf. Koffka 1932. Para una breve presentación de conjunto de la posición de Koffka en el campo de la experiencia cromática, véase Gilchrist 2006; 53-59.
} 
formación cromática deben ser explicados sobre la base de la distinción entre «materia cromática» y «modo de manifestación» del color, como funciones de la organización del campo visual, como un todo. Sobre esa base, distingue dos tipos de efectos diferentes, a saber: por un lado, el «incremento de diferencia» cromática, que en muchos casos se identifica con los fenómenos tradicionales de contraste; por otro, el «cambio de nivel» cromático, que se corresponde aproximadamente con lo que por lo regular se denomina transformación cromática, es decir, el cambio de un color en otro, y no la mera diferencia de contraste. En conexión con ambos principios, Koffka introduce, además, el concepto de «nivel neutral» que le permite formular el principio según el cual el nivel cromático general del campo visual se aproxima lo más posible al «nivel neutral» ${ }^{78}$. Sobre la base de nuevos experimentos, tales como los basados en la proyección de una sombra coloreada sobre fondos de diverso color ${ }^{79}$, Koffka muestra, entre otras cosas, que algunos fenómenos tratados tradicionalmente como fenómenos de contraste, es decir, de mero «incremento de diferencia», deben ser considerados, en realidad, como fenómenos de «cambio de nivel» ${ }^{80}$, aunque resulta altamente improbable que todos los fenómenos del primer tipo puedan ser reinterpretados como fenómenos del segundo tipo ${ }^{81}$. Koffka cree que el modelo explicativo basado en los dos principios mencionados y en

\footnotetext{
${ }^{78}$ Como reconoce expresamente, Koffka sigue aquí el camino abierto por Erich Jaensch (18831940), el psicólogo de Gotinga que mantuvo contacto epistolar con Husserl entre 1906 y 1922 y fue uno de los primeros en recibir productivamente los impulsos procedentes de su obra. Para la figura de Jaensch, véase Spiegelberg 1972; 41 s. Véase Koffka 1932; 331 ss.

${ }^{79}$ Para una breve explicación del así llamado «experimento de la sombra coloreada», véase Gilchrist 2006; 58 s.

${ }^{80}$ Cf. Koffka 1932; 340 ss.

${ }^{81}$ Cf. Koffka 1932; 349 ss.
} 
el concepto de «nivel neutral» permite explicar de modo más satisfactorio los diversos fenómenos vinculados con la «constancia cromática», tal como ésta se experimenta en la experiencia visual corriente. La «constancia cromática» empeora significativamente cuando el color de la iluminación es muy saturado y cuando su composición se hace cada vez más monocromática, al punto de que en el caso extremo de la iluminación monocromática todos los objetos reflejan uno y el mismo tipo de luz, aunque con diferentes intensidades. Tales condiciones extremas de iluminación impiden, pues, que el «cambio de nivel» cromático y el cambio de la luz reflejada por los diversos objetos puedan compensarse el uno al otro, con la consecuencia de que la «constancia cromática» se pierde total o parcialmente ${ }^{82}$. Todo esto muestra, una vez más, que el fenómeno de la «constancia cromática» es función de la articulación total del campo visual.

\section{f) K. Bühler}

Por último, también merece ser mencionado el aporte de Karl Bühler que es famoso, sobre todo, por sus contribuciones a la teoría del lenguaje $\mathrm{e}^{83}$. Ha realizado además una cantidad de importantes contribuciones a la psicología, tanto en el ámbito de la percepción del espacio y el tiempo ${ }^{84}$, en el del desarrollo infanti1 ${ }^{85}$ y en el de la consideración filosófica y psicológica del fenómeno anímico, así como en el nivel propiamente humano y en el nivel animal ${ }^{86}$. En lo que concierne

\footnotetext{
${ }^{82}$ Cf. Koffka 1932; 352.

${ }^{83}$ Cf. esp. Bühler 1933a, 1933b y 1934.

${ }^{84}$ Cf. Bühler 1913.

${ }^{85}$ Cf. Bühler 1918.

${ }^{86}$ Cf. esp. Bühler 1936.
} 
al ámbito de problemas vinculados con la percepción visual y la experiencia cromática, hay que mencionar su investigación de 1922 sobre el modo de manifestación de los colores, la cual tuvo una importante influencia sobre Katz, como lo muestra el hecho de que éste le dedica un parágrafo independiente en su obra de $1930^{87}$. También Bühler se centra en la problemática vinculada con el fenómeno de la «constancia cromática». Bühler partía de la asunción errónea de la función estimuladora de la visión que cumple el aire iluminado, que determinaría no sólo la percepción del vacío sino también la impresión de iluminación en todas las partes del espacio. Este punto resultaba importante para Bühler, por la sencilla razón de que la teoría de Katz, presentada originalmente en 1911, presuponía necesariamente que la iluminación tiene que poder ser percibida. La pregunta era entonces cuáles son los estímulos que lo hacen posible. A ello se agrega el hecho de que la iluminación contribuye necesariamente a la percepción del color de las cosas, la cual sólo puede ser explicada como tal por un recurso al que Bühler denomina el "principio de duplicidad» (Duplizitätsprinzip). Éste establece que todos los fenómenos de constancia en la percepción están basados en dos fundamentos empíricos, a saber: «proyecciones cósicas» (Dingprojektionen) y «criterios circunstanciales» (Umstandskriterien). Más allá del unánime rechazo posterior de su hipótesis concerniente a los factores que explicarían la percepción lumínica, el énfasis puesto por Bühler en la función del contexto, a la hora de explicar la percepción visual y la experiencia cromática con referencia al fenómeno de la «constancia cromática», aproxima fuerte-

\footnotetext{
${ }^{87}$ Cf. Bühler 1922; véase la discusión en Katz 1930; § 63, de la cual una primera versión se encuentra en Katz 1924, donde se reseña la obra de Bühler.
} 
mente su concepción a las posiciones más características de la «psicología de la forma».

\section{Interludio: el «cuerpo vivido (propio)» y el desarrollo de la fenomenología post-husserliana}

Uno de los rasgos característicos más salientes de la fenomenología del período de postguerra y, en general, de la segunda mitad del siglo xx reside en la centralidad que adquiere la problemática vinculada con el «cuerpo propio»o «cuerpo vivido» (Leib), es decir, experimentado como vivo en primera persona, por oposición no sólo al cuerpo inerte, sino también al cuerpo viviente, pero no experimentado como vivo en primera persona (Körper). Esta constatación tiene un doble alcance, que conviene aclarar.

Por una parte, hay que señalar que la temática del «cuerpo vivido (propio)» irrumpe por primera vez en el primer plano de la atención filosófica con el advenimiento de la fenomenología. Fue la nueva concepción de la filosofía y su método que inauguró la fenomenología la que hizo posible que la temática vinculada con el «cuerpo vivido (propio)» adquiriera un protagonismo filosófico sin precedentes, pues dicha nueva concepción puso, por primera vez, las bases necesarias para dar justicia al papel fundamental e irreductible que corresponde a la dimensión de la «corporalidad vivida (propia)» en la constitución integral del sentido experimentado. Por otra parte, y es el segundo aspecto a tener en cuenta, se añade el hecho de que en el desarrollo mismo del pensamiento fenomenológico, ya en el caso del propio Husserl, la elaboración de una concepción destinada a dar cuenta del sentido de la experiencia en su totalidad condujo, de modo 
gradual pero irreversible, a la puesta de manifiesto de niveles cada vez más básicos y elementales de constitución y apertura de sentido, situados muy por debajo del umbral que marca la entrada al campo de lo que habitualmente se entiende por la "conciencia», en el sentido más marcadamente cognitivista del término. Dicho de otro modo: el intento por esclarecer en su origen y sus fundamentos la estructura de la experiencia como un todo, partiendo de las prestaciones constitutivas de la conciencia, conduce, en definitiva, a una radicalización y ampliación de la misma idea de «conciencia», que la libera de la sujeción inicial al entorno del "conocimiento», en el sentido estrecho del término. Hay toda una amplísima variedad de formas y niveles de acceso al sentido - es decir, de lo que Husserl piensa bajo el concepto de la «intencionalidad»que revisten un carácter atemático, no objetivante $\mathrm{y}$, en general, no cognitivo, las cuales por tanto no se dejan apresar adecuadamente desde el punto de vista correspondiente a la propia descripción fenomenológica, por medio de los esquemas conceptuales que están cortados a la medida para describir las diversas formas de la «intencionalidad cognitiva», en el sentido estrecho del término. Piénsese, por caso, en todo el ámbito de fenómenos vinculados con el tipo de apropiación de sentido que posibilitan las pulsiones corporales y las tendencias instintivas más básicas, una temática en la que Husserl, una vez avistada, fue profundizando con el correr del tiempo ${ }^{88}$.

Ahora bien, a pesar de los valiosísimos esfuerzos de Husserl por hacer fenomenológicamente accesible el estrato de

\footnotetext{
${ }^{88}$ En este sentido, véase ya los desarrollos referidos al «cuerpo vivido (propio)», en conexión con el problema de la constitución de la «realidad anímica» (seelische Realität), contenidos en los §§ 35-42 de Ideen II (= Husserl [1912-1928]).
} 
constitución correspondiente al «cuerpo vivido (propio)» $\mathrm{y}$ por poner de relieve la importancia de su contribución a la constitución total del sentido, Husserl queda, al menos a los ojos de varios de sus discípulos más brillantes, atado en gran medida a un paradigma de constitución, en el cual las prestaciones cognitivas juegan un papel excesivamente protagónico, cosa que imprime un sesgo cognitivista excesivamente unilateral a su concepción de conjunto. No es casual que Husserl se oriente a partir de la noción, lastrada de fuerte carga cognitiva, de la «conciencia» (Bewußtsein), ni lo es tampoco que, a la hora de designar las estructuras de intencionalidad que pretende tematizar, se oriente a partir del par de conceptos complementarios nóesis/nóema, que aplica de modo genérico e indiferenciado a todas las formas de la experiencia del sentido. Los dos seguidores de Husserl filosóficamente más penetrantes e independientes, Max Scheler (1874-1928) y Martin Heidegger (1889-1976), reaccionaron muy pronto con vigor frente a este sesgo cognitivista de la posición husserliana.

Por un lado, Scheler extiende la problemática husserliana de la intencionalidad al ámbito total de la emocionalidad, y toma distancia de la orientación básicamente cognitivista que cree detectar en Husserl. Aunque de modo parcial y fragmentario, Scheler elabora una concepción del «cuerpo vivido (propio)» ${ }^{89}$, y critica también la posición de Husser ${ }^{90}$. Por otro lado, Heidegger, ya desde sus primeras lecciones académicas en Friburgo en los años de 1919-1921, denunció que la fenomenología de Husserl había quedado presa del mismo prejuicio que afectaba a toda la corriente principal de la tradición filosófica precedente, a saber: la tesis del «primado gene-

\footnotetext{
${ }^{89}$ Véase Scheler 1913-1916; 399.

${ }^{90}$ Véase Scheler 1923; 244 ss.
} 
ral de lo teórico», como la llama Heidegger, la cual impedía hacerse cargo adecuadamente en el plano de la elucidación filosófica de las estructuras más elementales de la experiencia de sentido, tal como ésta acontece en el ámbito del mundo. Heidegger no elaboró él mismo una concepción del «cuerpo vivido (propio)», aunque ya en tiempos muy tempranos reconoció una importancia fundamental (grundlegende Bedeutung) a esa temática ${ }^{91}$, a la que, mucho tiempo después, a fines de los años sesenta, en un seminario sobre Heráclito compartido con Eugen Fink (1905-1975), todavía considera nada menos que como «el problema más difícil»» ${ }^{92}$. En rigor, ha sido Heidegger el que, en gran medida, ha motivado lo que puede llamarse el posterior «giro corporalista» de la fenomenología, especialmente en la fenomenología francesa, tal como ocurre de diferentes modos, en Jean-Paul Sartre (1905-1980), Maurice Merleau-Ponty (1968-1961) y Michel Henry (1922-2002); pero también en la alemana, tal como acontece en Hermann Schmitz (1928-). Todo ello, por cierto, muy a pesar del hecho de que el propio Heidegger no haya abordado el problema del «cuerpo vivido (propio)» de modo específico ${ }^{93}$.

\footnotetext{
${ }^{91}$ Cf. Heidegger 1919; 210.

${ }^{92}$ Cf. Heidegger - Fink 1966/67; 236: «Das Leibphänomen ist das schwierigste Problem».

${ }^{93}$ Heidegger tampoco se ocupó de modo específico de la problemática del color, pero algunas observaciones ocasionales revelan claramente la filiación decididamente fenomenológica de su posición, en particular a la hora de oponerse a todo enfoque reduccionista. Refiriéndose a la explicación habitual que considera los colores como meras impresiones subjetivas y los reduce a longitudes de onda y velocidades de oscilación, comenta Heidegger en tono marcadamente crítico: «Eine solche Erklärung der Empfindung sieht sehr wissenschaftlich aus und ist es doch nicht, sofern der Bereich der Empfindungsgegebenheit und das, was erklärt werden soll, nämlich die Farbe als gegebene, sogleich verlassen werden. Überdies wird nicht beachtet, daß noch ein Unterschied besteht, ob wir bei einer Farbe die bestimmte Farbigkeit eines Dinges meinen, dieses Rot am Ding, oder die Rotempfindung als im Auge gegebene. Es bedarf einer sehr verwickelten und künstlichen Einstellung, um die Empfindungsfarbe als solche im Unterschied zur Dingfarbe zu fassen. Achten wir indes - unter Fernhaltung jeder Erkenntnistheorie - auf die Gegebenheit der Dingfarbe, z. B. auf das Grün eines Blattes, dann findet sich da nicht das mindeste von einer Ursache, die eine Wirkung in uns auslöst. Wir vernehmen niemals das Grün des Blattes als Wirkung auf uns, sondern als Grün des Blattes»
} 


\section{El color en la fenomenología \\ del «cuerpo vivido»: M. Merleau-Ponty y H. Schmitz}

Entre los representantes más salientes del «giro corporalista» de la fenomenología conviene considerar brevemente, como se anticipó ya, las concepciones de Merleau-Ponty y Hermann Schmitz, quienes desde ópticas muy diferentes han hecho aportes significativos al problema que nos ocupa.

\section{a) M. Merleau-Ponty}

En la que cuenta como su obra principal, Merleau Ponty lleva a cabo un tratamiento de conjunto de la problemática propia de una fenomenología de la percepción ${ }^{94}$. Desde un comienzo, el análisis llevado a cabo por Merleau-Ponty se caracteriza por su abierta oposición a todo enfoque de carácter atomístico o elementarizante, como lo es el propio de las concepciones asociacionistas características del empirismo, que están basadas en prejuicios naturalistas como el que adquiere expresión en la «suposición (hipótesis) de constancia», mencionada más arriba $^{95}$. Frente a esto, la perspectiva dominante en el análisis desarrollado por Merleau-Ponty es la que abre el punto de partida en el fenómeno del «cuerpo vivido (propio)». La percepción no puede ser adecuadamente comprendida en su unidad irreductible, ni desde una perspectiva objetivista o naturalizada, ni tampoco desde una perspectiva subjetivista o espiritualizada, al modo en que lo pretenden las concepciones intelectualistas que buscan acceder al ámbito

(cf. Heidegger 1935/36; 162 s.).

${ }^{94}$ Véase Merleau-Ponty 1945.

${ }^{95}$ Cf. Merleau-Ponty 1945; 9-33. 
de la percepción orientándose a partir de fenómenos como la atención y, sobre todo, el juicio ${ }^{96}$. En el caso de la percepción, se trata de un fenómeno que posee un carácter primordial e irreductible, no sólo en razón del entrelazamiento de estructuras psíquicas (actos psicológicos) e ideales (esencias intencionales) que presenta su estructura interna, sino también por el hecho de quedar situada, desde el punto de vista del contenido que abre, en un ámbito de experiencia de carácter pre-judicativo o pre-categorial, aunque no por ello carente de articulación significativa. En último término, el peculiar tipo de apertura del mundo que facilita la percepción sólo puede ser comprendido adecuadamente desde la perspectiva más amplia que atiende al papel que desempeña, como tal, el «cuerpo vivido (propio)», pues es éste el que nos vincula de modo inmediato, pre-reflexivo, al mundo.

En su análisis concreto del fenómeno de la percepción, Merleau-Ponty, tal como lo había hecho ya Schapp y siguiendo, al igual que éste, la inspiración proveniente de la concepción husserliana, parte de la constatación de que la percepción está, como tal, polarizada hacia el objeto o la cosa cuya unidad, a diferencia de lo que suponía Kant, no debe pensarse como el resultado de una actividad constitutiva de síntesis, de carácter intelectual. Ya en el nivel de la mera percepción, vale decir, de modo puramente existencial y no intelectual, la cosa es experimentada como idéntica en y a través de sus múltiples modos de aparición ${ }^{97}$. Por otra parte, la cosa se aparece como portadora de un conjunto de propiedades constantes, tales como forma, color, sonido, temperatura, peso, cualidades táctiles, etc., y ello de modo tal que las variaciones debidas

\footnotetext{
${ }^{96}$ Cf. Merleau-Ponty 1945; 34-63.

${ }^{97}$ Cf. Merleau-Ponty 1945; 347 ss.
} 
a cambios de perspectiva no cuentan como variaciones de la $\operatorname{cosa}^{98}$. Y, al igual que Schapp, Koffka y los restantes representantes de la "psicología de la forma», Merleau-Ponty asume que buena parte de la tarea de una adecuada fenomenología de la percepción consiste, precisamente, en dar cuenta de la posibilidad y la estructura de tales constantes perceptivas, sin reinterpretarlas indebidamente como productos de actos sintéticos de carácter intelectual, sino, más bien, poniendo de relieve su conexión con las condiciones que determinan el «punto de madurez» propio de la percepción adecuada o privilegiada, es decir, aquella que da, como tal, la cosa ${ }^{99}$.

Ahora bien, en el caso específico del color, esto implica dar una interpretación adecuada del fenómeno de la «constancia cromática», que como se vio, está en el centro de la mayor parte de las concepciones fenomenológicas ${ }^{100}$. Aquí Merleau-Ponty pasa revista de modo crítico a lo más relevante de la discusión desarrollada en los autores precedentes, tales como Hering, Gelb, Katz, etc. En concordancia con la orientación general de la concepción de la percepción desarrollada en la obra, el punto sistemático central de su discusión del problema consiste en poner de manifiesto el hecho de que el fenómeno de la «constancia cromática» no puede ser comprendido adecuadamente ni en términos empiristas o naturalistas ni tampoco en términos intelectualistas o idealizados. En particular, no se trata de una «constancia ideal», reconocida como tal en la reflexión ${ }^{101}$. $\mathrm{El}$ «color» percibido no es, por lo mismo, el color puro, dado

\footnotetext{
${ }^{98}$ Cf. Merleau-Ponty 1945; 345 ss.

${ }^{99}$ Véase Merleau-Ponty 1945; 348 s., donde Merleau-Ponty, siguiendo a Schapp, menciona las «normas» de distancia, orientación y constancia.

${ }^{100}$ Cf. Merleau-Ponty 1945; 351 ss.

${ }^{101}$ Cf. Merleau-Ponty 1945; 351 s.
} 
en abstracto, sino que es siempre el color de la cosa, ya que la percepción va hacia la cosa atravesando, por así decir, el color: éste se aparece como asociado, vinculado a ella, en la medida en que es irradiado por ella ${ }^{102}$. La diferencia formal-categorial establecida por Katz entre "color de área» o "color fílmico» $\mathrm{y}$ «color de superficie» permite hacer justicia, entre otras cosas, a la peculiar asociación con la cosa que caracteriza al color propio de ella, por oposición a colores no vinculados a cosas, en general, y también, en particular, a los diversos modos de aparición de la cosa en contextos en los cuales los efectos lumínicos y cromáticos no se corresponden con lo que demanda la percepción adecuada. En cualquier caso, el punto decisivo es que se trata de fenómenos y distinciones que se explican a partir de la estructura de la propia percepción, y no en términos de variaciones de una materia sensible pretendidamente invariable a la que posteriormente se le imponen determinadas significaciones conceptuales ${ }^{103}$.

Una variedad de experimentos permite mostrar, a juicio de Merleau-Ponty, que tanto la «constancia cromática» como los diversos fenómenos de cambio de color sólo pueden comprenderse, en último término, por referencia a la organización total del campo perceptivo y sus correspondientes modificaciones ${ }^{104}$. En particular, la conexión del fenómeno de la «constancia cromática» con la articulación del campo y el fenómeno de la iluminación puede considerarse, explica Merleau-Ponty, un hecho establecido ${ }^{105}$. Siguiendo a Schapp, Merleau-Ponty señala la importancia y la peculiaridad de la función que cum-

\footnotetext{
${ }^{102}$ Cf. Merleau-Ponty 1945; 352.

${ }^{103}$ Cf. Merleau-Ponty 1945; 353 s.

${ }^{104}$ Cf. Merleau-Ponty 1945; 354 ss.

${ }^{105}$ Cf. Merleau-Ponty 1945; 356.
} 
plen los efectos lumínicos en la percepción de $\operatorname{cosas}^{106}$ : en ella, la claridad y los reflejos cumplen su función no reteniendo la mirada, sino conduciéndola hacia la cosa misma ${ }^{107}$. En la medida en que muestra una clara dependencia de aspectos como la distancia y la orientación, la «constancia cromática» revela también su dependencia de nuestra situación corporal ${ }^{108}$. Por su parte, la claridad lumínica, tal como la que provee la luz del día o bien la luz eléctrica que habitualmente la sustituye, no es ella misma visible de modo directo ni es color. En tanto instaura una cierta atmósfera lumínica, se sitúa ella misma, por así decir, «más acá» de todas las diferencias de colores y efectos lumínicos, tiende a ser cromáticamente neutral, vale decir, tiende al «cero de color» ${ }^{109}$. De modo correlativo, los objetos se distribuyen los colores del espectro según el grado y el modo de su resistencia a esta atmósfera lumínica. Por lo mismo, todo «color-quale» está mediado por un cierto «color función», es decir, se determina por referencia a un nivel de luminosidad que es variable, pero que en nuestra vida normal se corresponde con la atmósfera propia de la luz del día y de la luz eléctrica «neutral» que la sustituye. Un cambio en tales condiciones contextuales, tal que el medio «neutral» es sustituido por uno «coloreado», trae consigo toda una serie de trasposiciones que conducen a una reformulación integral del correspondiente esquema cromático y lumínico ${ }^{110}$.

Por tanto, la iluminación no es aquí sino un momento dentro de una estructura compleja cuyos otros momentos son la organización del campo perceptivo, tal como la realiza nues-

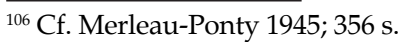

${ }^{107}$ Cf. Merleau-Ponty 1945; 357 s.

${ }^{108}$ Cf. Merleau-Ponty 1945; 358 s.

${ }^{109}$ Cf. Merleau-Ponty 1945; 359.

${ }^{110}$ Cf. Merleau-Ponty 1945; 359.
} 
tro cuerpo, y la cosa iluminada, en su constancia ${ }^{111}$. Siguiendo a Katz, Merleau-Ponty señala que hay una cierta «lógica de la iluminación» (logique de l'éclairage) o bien una "síntesis de la iluminación» (synthèse de l'éclairage), que entraña la organización total del campo perceptivo, la cual, dado que los colores se presentan siempre como colores de cosas, comprende, en último término, todos los caracteres sensoriales y toda la significación de los objetos, unificados al modo de un siste$\mathrm{ma}^{112}$. En tal sentido, la «constancia cromática» no es más que un momento abstracto de la constancia de las cosas, la cual se funda, a su vez, en la conciencia primordial del mundo como horizonte de todas nuestras experiencias: no es, pues, la percepción de colores constantes la que funda la «creencia» en cosas constantes, sino que, por el contrario, la percepción sólo puede encontrar colores constantes en la medida en que ella misma está abierta, por sí misma, al mundo y las cosas ${ }^{113}$.

\section{b) H. Schmitz}

La figura de Hermann Schmitz apenas empieza a ser conocida algo más ampliamente, a pesar de tratarse de un autor muy productivo que ha publicado de modo incesante desde hace más de cuarenta y cinco años. Nacido en Leipzig entre 1949 y 1953, Schmitz estudió en Bonn donde se doctoró en 1955 con una tesis sobre Hegel. A partir de 1958 trabajó en Kiel, donde primero se habilitó con un trabajo sobre el pensamiento de vejez de Goethe. Posteriormente, en 1971 alcanzó la posición de Profesor Ordinario que mantuvo hasta su retiro en 1993.

\footnotetext{
${ }^{111}$ Cf. Merleau-Ponty 1945; 359 s.

${ }^{112}$ Cf. Merleau-Ponty 1945; 361 s.

${ }^{113}$ Cf. Merleau-Ponty 1945; 362.
} 
En el ámbito de la filosofía académica alemana, a Schmitz le correspondió casi siempre el papel de una figura marginal, practicamente ignorada por sus colegas, una situación que empezó a cambiar en alguna medida sólo recientemente, en todo caso con posterioridad a su retiro de la cátedra. Al mismo tiempo, Schmitz declaró desde muy temprano su pretensión de ser el iniciador de una nueva corriente de pensamiento, la por él llamada «Nueva Fenomenología», que superaría definitivamente todas las posiciones elaboradas con anterioridad en la escuela fenomenológica, desde Husserl y Heidegger hasta Merleau-Ponty y los representantes más recientes de la fenomenología del «cuerpo vivido (propio)». En cualquier caso, sólo muy recientemente el pensamiento de Schmitz comenzó a ser objeto de algún tipo de recepción positiva por parte de colegas que reconocen expresamente sus méritos ${ }^{114}$.

La obra de Schmitz se caracteriza por su gran extensión y por la peculiaridad, poco menos que idiosincrática, de su contenido. Dejando de lado toda una serie de obras dedicadas a la interpretación de autores canónicos de la historia de la filosofía, como Aristóteles, Kant, Husserl y Heidegger, algunas de ellas de una considerable extensión, lo fundamental de la tarea de Schmitz ha consistido en la elaboración de una concepción filosófica original. Su obra principal, que lleva un título muy poco atractivo y aún menos indicativo de su real contenido: System der Philosophie, abarca diez volúmenes, que fueron publicados sucesivamente entre 1964 y 1980. A ella se añade un amplio conjunto de escritos posteriores que re-

\footnotetext{
${ }_{114}$ Véase, en particular, la recepción de la concepción de Schmitz en Böhme 2003; esp. 45 ss., 59 ss., 88 ss., et passim. Véase también Waldenfels 2000; 267-273, 276-284, cuya evaluación de la posición de Schmitz, desde una perspectiva mucho más próxima a Husserl, es, sin embargo, eminentemente crítica.
} 
sumen la concepción expuesta en la obra o bien desarrollan aspectos particulares o consecuencias ulteriores de dicha concepción. Como es obvio, no es posible proveer aquí siquiera una idea somera de la filosofía de Schmitz ${ }^{115}$, que en su mismo punto de partida contiene incluso una interpretación de conjunto relativa al desarrollo de la visión del hombre y el mundo humano en la cultura y la filosofía occidental desde sus orígenes griegos ${ }^{116}$. En su núcleo central, sin embargo, la concepción de Schmitz debe verse como una fenomenología del «cuerpo vivido (propio)», cuya novedad principal consiste en la radicalidad de sus puntos de partida y en su vocación netamente empírica, reacia a toda tentación idealizante. Lo que Schmitz se propone tematizar fenomenológicamente es la dimensión de lo que denomina «la experiencia vital no arbitraria» (die unwillkürliche Lebenserfahrung). Se trata de una dimensión encubierta, a lo largo de una compleja evolución histórica, por diversos estratos superpuestos de construcciones conceptuales deudoras de interpretaciones artificiosas, que precipitan finalmente en la visión, dominante desde la Modernidad, según la cual el ser humano es un sujeto individual que posee un mundo interior privado, enfrentado al mundo exterior que toma por objeto la ciencia natural ${ }^{117}$.

Tal dimensión de «experiencia vital no arbitraria», pasada una y otra vez por alto, es la que corresponde al ámbito del «cuerpo vivido (propio)» (Leib), que Schmitz distingue tajantemente tanto del «cuerpo orgánico» (Körper) como tam-

\footnotetext{
${ }^{115}$ Para una presentación sintética de los aspectos principales de la concepción de Schmitz, véase Soentgen 1998.

${ }^{116}$ Para este aspecto, véase ahora la presentación sucinta en Schmitz 2009a; 9-27.

${ }^{117}$ Para una breve caracterización del punto de partida histórico-crítico de la «Nueva Fenomenología», en conexión con el concepto de la «base abstractiva» (Abstraktionsbasis) de una determinada cultura, véase Schmitz 2009b; 11-15.
} 
bién del «alma» (Seele). Justamente, la superposición con la imagen del cuerpo orgánico que nos hacemos a través de la vista es uno de los factores que, a juicio de Schmitz, más dificultan la adecuada descripción de las estructuras fenoménicas pertenecientes al nivel del «cuerpo vivido (propio)», las cuales reclaman la puesta en juego de un repertorio categorial específico, completamente diverso del empleado habitualmente. Así, por ejemplo, Schmitz insiste en que en el nivel de experiencia que corresponde al «cuerpo vivido (propio)» no tenemos acceso alguno a algo así como «órganos», sino que el «cuerpo vivido (propio)» se experimenta, se «siente» (spüren) bajo la forma de «islas corporeovividas» (Leibinsel), que poseen una posición espacial absoluta, y no relativa, y que no se corresponden, sin más, con los órganos que identifica el examen exterior del cuerpo, considerado, por así decir, en perspectiva de tercera persona ${ }^{118}$. La dinámica propia de la experiencia del «cuerpo vivido (propio)» se explica en términos de determinaciones y oposiciones categoriales tales como «estrechez» (Enge) y «amplitud» (Weite), «dirección» (Richtung), «tensión» (Spannung) e «hinchazón» o «tumefacción» (Schwellung), «intensidad» (Intensität) y «ritmo» (Rhythmus), «tendencia epicrítica» (epikritische Tendenz) y «tendencia protopática» (protopathische Tendenz). Se trata del conjunto de categorías que conforman lo que Schmitz denomina en ocasiones el «alfabeto de la corporalidad vivida (propia)» (Alphabet der Leiblichkeit $)^{119}$. En la elaboración de tal repertorio categorial todo ocurre como si las distinciones fueran obtenidas

\footnotetext{
${ }^{118}$ Para el tratamiento del «cuerpo vivido (propio)», véase Schmitz 1965. Para algunos de los problemas que presenta la tajante separación de «cuerpo vivido (propio)» (Leib) y «cuerpo orgánico» (Körper), véase Soentgen 1998; 58 ss.

${ }_{119}$ Cf., por ejemplo, Schmitz 2008; 44-49; para una presentación de conjunto del repertorio categorial empleado por Schmitz, véase Soentgen 1998; 20-26.
} 
a partir de una atenta observación que comienza por el más simple y elemental «sentir», y que, al menos inicialmente es realizada, por así decir, «a ojos cerrados», a fin de evitar toda superposición con elementos procedentes de la experiencia objetivada del propio cuerpo, que, como tal, ya no se corresponde con el «cuerpo vivido (propio)».

También en el caso de la percepción, Schmitz elabora un modelo original, fuertemente divergente de los enfoques fenomenológicos clásicos. Ante todo, Schmitz rechaza el esquema clásico husserliano de interpretación de la intencionalidad basado en la distinción entre «acto» $\mathrm{y}$ «contenido objetivo» para dar cuenta de la estructura de la percepción, a la cual intenta caracterizar, en cambio, por medio de la noción de «comunicación corporeovivida» (leibliche Kommunikation), de la cual los dos tipos principales vienen dados por lo que Schmitz denomina «integración corporeovivida» (Einleibung) y «distensión corporeovivida» (Ausleibung) $)^{120}$. Cada una de esas dos formas fundamentales de «comunicación corporeovivida» tiene lugar, en sus diversas posibles formas, según la estructura que la correspondiente experiencia traiga consigo o bien de la suerte de concentración sobre sí o de la suerte de derramarse en la amplitud, con ocasión de lo en cada caso percibido. Por otro lado, desde el punto de vista que atiende a lo que en cada caso se percibe, Schmitz introduce aquí un innovador esquema explicativo que, primero, considera de modo general los «decursos configuracionales» (Gestaltverläufe) asociados a la percepción del movimiento y los «caracteres sinestésicos» (synästhetische Charaktere) de la percepción. Luego, distingue entre la percepción «cosas» (Dinge), de «semicosas» o «me-

${ }^{120}$ Cf. Schmitz 1965; §§ 241-243; véase también la caracterización de ambas formas fundamentales de la «comunicación corporeovivida» en Schmitz 2009b; 30-45. 
diacosas» (Halbdinge) y de "cualidades», donde el aspecto más innovador viene dado, sin duda, por el reconocimiento de la categoría ontológica intermedia de las «semicosas», que comprende toda una gama de fenómenos tan diversos como los diferentes tipos de atmósferas, el viento, la mirada, la voz, los sonidos musicales, los sentimientos, el tiempo, etc. ${ }^{121}$ En su análisis de los diversos tipos de percepción, Schmitz no sólo atiende a la diferencia de cada sentido, sino también a las diferencias categoriales del contenido en cada caso percibido: hay percepción visual, auditiva, táctil, gustativa, etc., pero en cada caso lo que se nos ofrece puede revestir la forma de una «cosa», de una «semicosa» o «mediacosa» o bien de una «cualidad», y ello también en conexión con los correspondientes «decursos configuracionales». Por otro lado, Schmitz rechaza la distinción tajante entre distintos tipos de percepciones vinculadas con diferentes sentidos, y enfatiza, en cambio, la unidad interna de lo percibido, tal que nunca tenemos ante nosotros algo experimentado como dotado de meras cualidades visibles, tangibles $\mathrm{u}$ olfativas. Toda cualidad perscibida revela siempre ya un conjunto de cualidades asociadas que, en defintiva, remiten a la unidad constitutiva de aquello que en cada caso se percibe. Así, por ejemplo, los diversos colores percibidos aparecen asociados a otro tipo de cualidades sensibles, tal como se pone de manifiesto allí donde se distingue entre colores cálidos y fríos, etc. Por lo mismo, todo enfoque de carácter aislacionista o elementarizante se muestra, desde un comienzo, incapaz de hacer justicia a la complejidad de los fenómenos perceptivos ${ }^{122}$.

\footnotetext{
${ }^{121}$ Cf. Schmitz 1965; § 245.

${ }^{122}$ A este respecto, véase la crítica a los prejuicios sobre la percepción, en particular, los procedentes del «sensualismo», en Schmitz 1965; § 236, esp. 8 ss.
} 
En lo que toca, en particular, a la percepción visual y la experiencia del color, se puede decir que el análisis de Schmitz apunta a esclarecer su estructura, sin perder contacto al reintroducir el fenómeno de la visión, con la dimensión de experiencia abierta originariamente «a ojos cerrados». Dicho de otro modo: también el análisis de la percepción visual se atiene al mismo repertorio de categorías elaborado para dar cuenta del ámbito fenoménico del «cuerpo propio (vivido)» y de la experiencia perceptiva, en general. En lo que concierne, en primer lugar, a los "decursos configuracionales", Schmitz enfatiza que la «sugestión de movimiento» (Bewegungssuggestion) tiene lugar, sobre todo, a través de la percepción auditiva, ya se trate de música o de mero sonido, y no tanto a través de la percepción visual, olfativa, etc. ${ }^{123}$ Distinta es la situación en el caso de los «caracteres sinestésicos», pues aquí los colores juegan un papel mucho más importante. Ya se mencionó el ejemplo clásico de la asociación de los diversos colores con las sensaciones térmicas de calidez y frialdad. A ello se añade la conexión de los diversos colores, el brillo, la opacidad, etc. con propiedades como la blandura, la dureza, la consistencia, la densidad, el volumen, la profundidad, el peso. Schmitz considera aquí también los efectos lumínicos conectados con los fenómenos de la claridad y el brillo, en particular, tal como se dan en el caso del fuego. Pone de relieve, siguiendo a W. Koch y otros, la estrecha asociación que mantiene el brillo ígneo con el color rojo, todo lo cual comporta diversos elementos sinestéticos, vinculados con sensaciones térmicas, experiencias de expansión, etcétera. ${ }^{124}$

\footnotetext{
${ }^{123}$ Cf. Schmitz 1965; § 238.

${ }^{124}$ Cf. Schmitz 1965; § 239, esp. 55 ss.
} 
En el caso de la percepción de «cosas» en general, Schmitz no va realmente mucho más allá de los resultados obtenidos por autores precedentes. En un primer momento, se concentra, sobre todo, en el intento por precisar si y en qué medida se debe apelar al modo habitual de explicar el contraste entre las propiedades «auténticas» de una cosa, por caso, su «verdadero» color, como se da en la percepción "privilegiada», por un lado, y los modos de manifestación de carácter ocasional, que responden a diversas condiciones contextuales, por el otro ${ }^{125}$. En lo que concierne más específicamente a la estructura misma de la percepción de «cosas», Schmitz concede decisiva importancia al papel que cumple la percepción de «superficies» (Flächen), y adopta, en tal sentido, la distinción establecida por Katz entre «color de superficie» (Oberflächenfarbe), «color de área» o «color fílmico» (Flächenfarbe) y «color espacial» $\mathrm{O}$ «color de volumen» (Raumfarbe). La percepción de «superficies» en la cual se funda la aparición de «cosas», en el sentido preciso de objetos corpóreos tridimensionales, está estructuralmente vinculada, como hizo notar ya Katz, con la percepción de «colores de superficie»: ni el «color de área» ni el «color de volumen» pueden contribuir de modo directo a la presentación perceptiva de cuerpos sólidos ${ }^{126}$.

En la introducción de la noción de «semicosa» («mediacosa») reside, como se ha dicho, uno de los aspectos más innovadores de la concepción schmitziana de la percepción. Sin embargo, en lo que concierne específicamente al modo en que se presenta el color en conexión con la percepción de «semicosas» («mediacosas»), Schmitz sólo provee unas cuantas observaciones aisladas. La más relevante concierne a la

\footnotetext{
${ }^{125}$ Cf. Schmitz 1965; § 246, esp. 149 ss.

${ }^{126}$ Cf. Schmitz 2009b; 64 ss.
} 
relación general entre «semicosas» («mediacosas») y «cualidades», cuya identificación Schmitz rechaza tajantemente. Al igual que en el caso del movimiento, también aquí sostiene Schmitz que la percepción de «semicosas» («mediacosas») se asocia principalmente al sonido, mientras que no resulta tan nítida en el caso del color, el olor, etc. Sin embargo, Schmitz piensa que indudablemente hay colores que constituyen «semicosas» («mediacosas»), allí donde, por caso, adquieren un cierto carácter substancial en relación con el brillo. Así, por ejemplo, las manchas luminosas aparecen en determinados contextos perceptivos como (cuasi-)sustratos que se permanecen a través de toda una serie de figuras o manifestaciones cambiantes, y algo semejante ocurre con la percepción de la noche en condiciones de completa oscuridad, la cual no es vista ni como una cosa ni tampoco como una mera cualidad de algo diferente ${ }^{127}$.

Por último, Schmitz considera también el caso de la percepción de cualidades. En lo que concierne específicamente al color, Schmitz parte del rechazo de toda teoría de la composición o mezcla y, a tal efecto, distingue nítidamente entre lo que serían «cualidades mixtas» (Mischqualitäten) y «cualidades intermedias» (Zwischenqualitäten). Así, por ejemplo, el color naranja es un «color intermedio» entre el amarillo y el rojo, pero no representa él mismo una mezcla de amarillo y rojo, sino que debe considerarse como un color sui generis, dotado de su propia especificidad ${ }^{128}$. La noción de "color intermedio» resulta aquí de utilidad para poder dar cuenta del hecho de que no todos los colores se sitúan entre otros colores diferentes. Por caso, el verde puro no se sitúa, como tal, entre

\footnotetext{
${ }^{127}$ Cf. Schmitz 1965; § 245, esp. 125 ss.

${ }^{128}$ Cf. Schmitz 1965; § 250, 203 s.
} 
el azul y el amarillo, muy a pesar de que pueda ser obtenido por medio de la mezcla de esos dos colores. En cambio, de «colores mixtos», a diferencia de los «colores intermedios», sólo puede hablarse propiamente, en el mejor de los casos, allí donde se tratara de colores variables, en los cuales resaltan diferentes matices cromáticos concurrentes ${ }^{129}$. En el nivel correspondiente a los colores individuales más básicos no hay, sin embargo, posibilidad de mezcla o composición: por ejemplo, lo que es rojo no es verde, y viceversa ${ }^{130}$. En el caso de los colores, las diversas especies cualitativas parecen más estrechamente ligadas a los casos individuales a través de los cuales se individuan y encarnan, que en el caso de cualidades gustativas o sonoras. Esta diferencia puede guardar cierta relación con el carácter mucho más decididamente focalizado de la percepción visual, pero ello no excluye, explica Schmitz, que también exista el fenómeno de la imposibilidad de mezcla o composición en cualidades que no dependen de un campo perceptivo estructurado al modo del campo visual, tal como lo muestra el caso de las cualidades térmicas: ningún caso individual del calor puede ser, a la vez, caso individual del frío ${ }^{131}$. Como quiera que sea, queda en pie el hecho de que los colores básicos han provisto desde siempre el ejemplo más claro de la individuación de cualidades, el cual, por otro lado, ha conducido una y otra vez al intento de explicar la relación entre el individual percibido y la correspondiente especie en términos de teorías de la abstracción que el propio Schmitz considera, al menos en su pretensión universal, inaceptables, pues no se aplican, por ejemplo, al caso de la

\footnotetext{
${ }^{129}$ Cf. Schmitz 1965; § 250, 204.

${ }^{130}$ Cf. Schmitz 1965; § 250, 205 s.

${ }^{131}$ Cf. Schmitz 1965; § 250, 206 s.
} 
percepción de tonos musicales y melodías, por oposición a los meros sonidos o ruidos ${ }^{132}$.

\section{A modo de conclusión}

La notable relevancia filosófica de la problemática relativa a los colores resulta, sin duda, sorprendente. Lo que a primera vista parecería constituir una simple cuestión particular entre muchas otras, situada en una posición más bien marginal respecto de las grandes preguntas de la filosofía, ha concitado permanentemente la atención de los filósofos a lo largo de la historia en una medida que no guarda correspondencia alguna con esa aparente marginalidad. La razón parece obvia: más allá del interés que puede despertar por sí misma, la problemática relativa a los colores cumple también, en razón de su propia naturaleza, la función de un escenario privilegiado en el cual se confrontan y se ponen mutuamente a prueba diferentes concepciones ontológicas, gnoseológicas y metodológicas. En no pocas ocasiones, es la identidad misma de una determinada concepción de la filosofía lo que se pone en juego en tales debates que, vistos desde este ángulo, ya no pueden considerarse privados de ulteriores proyecciones fuera de los límites propios del problema específico sobre el cual versan.

También en el caso específico de las concepciones fenomenológicas del color vale lo dicho. El interés de los autores pertenecientes a la tradición fenomenológica por la problemática relativa a los colores queda, desde un comienzo, inscripto en

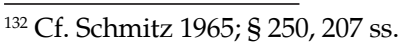


el marco mucho más amplio provisto por el intento de hacer justicia a un determinado modo de entender la experiencia, la realidad que se ofrece a través de ella y también la tarea misma de la filosofía. Todo ello, además, en el contexto polémico que provee la confrontación con los enfoques reduccionistas procedentes tanto del ámbito científico como del propiamente filosófico. En su decidida vocación anti-reduccionista, la fenomenología puede ser vista, en último término, como un intento por recuperar de modo metódicamente guiado en el nivel correspondiente a la reflexión filosófica, la realidad experimentada tal como ésta se presenta en el acceso inmediato al mundo de la vida. La «ingenuidad» de tal acceso inmediato al mundo de la vida aparece especialmente amenazada en una época en la cual, para decirlo con las palabras del segundo acápite citado al comienzo, hasta los niños que van a la escuela primaria creen saber ya con suficiente certeza que no hay realmente colores «en sí», ni sonidos «en sí», ni sabores «en sí», ni olores «en sí». En efecto, sobre la base de las explicaciones que han oído, suponen poder dar por descontado, cuando así razonan, que el mundo que se nos ofrece en la experiencia constituye, si no en su totalidad, al menos en una medida muy importante, una mera apariencia que debe ser explicada en su origen, sobre la base de determinados modelos explicativos de carácter causal-reductivo, por referencia a una estructura subyacente que no se revela de modo directo en la propia percepción. Sobre las aporías, muchas veces insalvables que encierra este modo de concebir la relación entre la experiencia y la realidad que se ofrece a través de ella, los propios niños no están siquiera mínimamente advertidos. Pero tampoco suelen estarlo, lamentablemente, los maestros de esos niños y la mayoría de los adultos, incluidos no pocas veces aquellos que se dedican profesionalmente al cultivo 
de la ciencia y que, a menudo, propugnan además una Weltanschauung que reclama para sí el prestigo de estar basada en la autoridad de esa misma ciencia. Se trata de nueva realidad cultural configurada decisivamente por el impacto que el éxito de la ciencia ha tenido sobre la propia «visión ingenua» del mundo. El resultado no fue, sin embargo, el de una pretendida superación definitiva de toda ingenuidad a través de la ilustración y el conocimiento científico, sino, más bien, el de un tendencial desplazamiento de la ingenuidad hacia el plano que concierne al tipo de actitud que debe cultivarse frente al hecho mismo de la ciencia con los problemas específicos de autocomprensión que plantea. Fue precisamente esta nueva realidad cultural la que en su día llevó a Husserl a formular la tesis, sólo aparentemente paradójica, según la cual un adecuado retroceso hacia la ingenuidad de la vida, en el plano de la reflexión filosófica, constituye el único camino para hacer posible la superación de la ingenuidad filosófica que subyace al proyecto objetivista de cientificidad, tal como éste caracteriza a la ciencia y a la filosofía de la Modernidad ${ }^{133}$. Según este diagnóstico es, pues, la propia vocación crítica de la filosofía la que impone esta necesidad de una adecuada recuperación de la ingenuidad de la vida, la cual, por tanto, nada tendrá que ver con lo que sería un liso y llano retorno, de suyo ilusorio e impracticable, a formas precríticas del pensamiento definitivamente superadas.

Las concepciones fenomenológicas del color y de la percepción destacan, sobre todo, por la profusión de los aportes

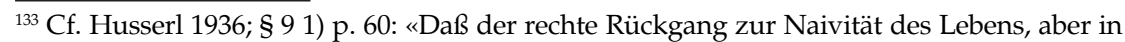
einer über sie sich erhebenden Reflexion, der einzig mögliche Weg ist, um die in der "Wissenschaftlichkeit" der traditionellen objektivistischen Philosophie liegende philosophische Naivität zu überwinden, wird sich allmälich und schließlich vollkommen erhellen und wird der schon wiederholt vorgedeuteten neuen Dimension die Tore eröffnen». 
de detalle que realizan a la descripción y la comprensión de una gran variedad de fenómenos particulares. En su orientación general, privilegian, pues, la pincelada breve que se detiene en la elaboración de cada detalle, frente al trazo grueso de la generalización que unifica o la palidez monocromática del esbozo que busca abarcarlo todo de una vez, en una sola mirada. Lejos de atentar contra la pretensión de una reivindicación filosófica de la experiencia como un todo que anima a estas mismas concepciones, tal modo de proceder suele constituir el mejor testimonio del carácter irreductible de lo que se ofrece de modo originario en dicha experiencia. En efecto, es en la rica variedad de su contenido y en la compleja articulación de sus estructuras donde han de buscarse, en definitiva, las credenciales que avalan de modo más fidedigno la pretensión de realidad de la experiencia misma. Frente a la robusta presencia de tal variedad de contenido y tal articulación estructural, poco pueden realmente las argumentaciones que, de modo más o menos constructivo, buscan degradar lo que se nos ofrece en el acceso inmediato al mundo de la vida al estatuto de lo que sería una mera apariencia, carente de genuina consistencia ontológica. Así pues, en su intento de reivindicación integral de la experiencia, la fenomenología no hace otra cosa, en definitiva, que ponerse al servicio de esa misma experiencia, elevando al plano de la reflexión consciente lo que se abre originariamente a través de ella y contribuyendo así a reforzar el vigor de su propia presencia. 


\section{Apéndice: Aristóteles y Goethe, en el camino de la fenomenología}

Aunque la irrupción de la fenomenología como una concepción filosófica diferenciada tuvo lugar recién a comienzos del siglo $x \mathrm{x}$, hubo desde siempre en la historia del pensamiento filosófico occidental, como se dijo al comienzo, pensadores cuyas concepciones pueden ser caracterizadas retrospectivamente como «fenomenológicas», en un sentido amplio y no excesivamente vinculante del término. En el caso concreto de la problemática de los colores, se podría mencionar un conjunto bastante amplio de autores que han adoptado posiciones anti-reduccionistas, de estilo en alguna medida afín al propio de los enfoques fenomenológicos. Dentro de ese conjunto, los casos más destacados son, probablemente, el de Aristóteles y, sobre todo, el de Goethe. Conviene, pues, hacer aquí alguna referencia, siquiera mínima, a las concepciones de ambos.

\section{a) Aristóteles}

Desde el punto de vista que aquí interesa, la concepción aristotélica reviste importancia no tanto por lo que concierne al análisis del contenido fenoménico de la percepción del color, asunto sobre el cual Aristóteles dice bastante poco sino, más bien, por el modo en el cual defiende una posición antireduccionista en el ámbito de la percepción de cualidades, sobre la base de una peculiar manera de concebir la relación entre los objetos sensibles y los sentidos. Aristóteles conoció posiciones reduccionistas como las del atomismo de Leucipo y Demócrito, quien concede de modo expreso un estatuto meramente convencional a las cualidades sensibles posteriormente llamadas «secundarias» y afirma, en cambio, la 
realidad de los átomos y el vacío ${ }^{134}$. Frente a esto, Aristóteles rechaza la posición de Demócrito, pues ella reduce (anágei) los sensibles propios a los sensibles comunes, en la medida en que intenta dar cuenta de cualidades como los colores, los sabores, los olores, etc., por referencia a propiedades geométricas de los átomos, tales como el tamaño y la figura. A juicio de Aristóteles, este modelo explicativo es metódicamente inadecuado e incapaz de dar cuenta del carácter específico de los sensibles propios, ya que las propiedades geométricas a las que se acude en calidad de explanans no guardan congruencia, desde el punto de vista estructural, con las que en su calidad de explanandum proveen el punto de partida y también el objeto de referencia último del intento de explicación así elaborado ${ }^{135}$. Por el contrario, Aristóteles mantiene en su propia concepción la cualidad como un género diferente e irreductible a la cantidad, y admite consecuente la existencia de una especie de cambio «según la cualidad», esto es, la «alteración» (alloíosis) que no resulta reductible, como tal, a ninguna otra especie de cambio.

Por lo mismo, a la hora de pensar la relación que vincula a los objetos sensibles y los sentidos, Aristóteles no se orienta a partir de un modelo explicativo que relegara las cualidades sensibles al ámbito meramente «subjetivo», por oposición a lo que serían las propiedades «objetivas» de las cosas. Aristóteles piensa las relaciones entre el mundo y el alma de un modo completamente diferente a las concepciones modernas que se orientan a partir de la oposición polar entre «objeto» $\mathrm{y}$ «sujeto». A juicio de Aristóteles, las cualidades sensibles están realmente presentes en los objetos sensibles, aunque, en prin-

\footnotetext{
${ }^{134}$ Cf. Demócrito 68 B 9 DK.

${ }^{135}$ Cf. Aristóteles, De sensu 4, 442a29-b23
} 
cipio, de modo sólo potencial, y vienen a su actualización tan sólo con el concurso del alma, a través de la percepción. En tal sentido, Aristóteles señala que el acto del sentido y el acto del objeto sensible son uno y el mismo, aunque el sentido y el objeto sensible son dos cosas diferentes ${ }^{136}$. Dicho de otro modo: lo que ocurre aquí es que dos potencialidades diferentes, una situada del lado del «sujeto», la capacidad de percibir, y otra situada del lado del «objeto», la capacidad de ser percibido, comparten un único y mismo acto en el cual convergen. De tal modo, cada una de ellas no puede llegar a su propia actualidad con independencia de la correspondiente actualización de la otra. Atendiendo al hecho de que dos potencias complementarias quedan elevadas así a un único y mismo acto, puede decirse que el modelo explicativo avistado por Aristóteles apunta a lo que puede denominarse «estructructuras triangulares de actualización».

Ahora bien, de fundamental importancia resulta el hecho de que dicho modelo explicativo no se aplica tan sólo al caso de las cualidades sensibles, tales como colores, olores, sabores, etc. Por el contrario, Aristóteles lo extiende también, de modo expreso, al caso de cosas que como el infinito y el tiempo no pueden ya contar como «cualidades secundarias», en el sentido moderno de la expresión ${ }^{137}$. Según esto, no hay razones realmente valederas para avalar la idea de que las cualidades sensibles poseen un estatuto de realidad secundario o derivado, respecto de otras determinaciones de los objetos corpóreos que deberían considerarse más básicas.

\footnotetext{
${ }^{136}$ Cf. Aristóteles, De anima III 2, 425b26.

${ }^{137}$ Para un desarollo más amplio de este punto, véase la discusión en Vigo 2002.
} 


\section{b) Goethe}

El caso más notorio de una concepción del color que puede caracterizarse como fenomenológica avant la lettre, es, sin duda, el de Goethe. En una carta a Theodor Conrad, escrita probablemente en octubre de 1910, ya Adolf Reinach caracterizó como fenomenológica, en su orientación general, la concepción que Goethe había intentado desarrollar en su Farbenlehre: «Pero hay una fenomenología de la luz y los colores; algo de este tipo pretendía Goethe en su doctrina de los colores. Una física de la luz es algo completamente diferente» ${ }^{138}$. En tiempos recientes, Theda Rehbock ha considerado el de Goethe como el ejemplo de una concepción cuyo objetivo reside en «salvar los fenómenos», siguiendo una línea que habían abierto ya Platón y, sobre todo, Aristóteles en su polémica contra el atomismo materialista de Demócrito ${ }^{139}$. En el caso de Rehbock, la doctrina de los colores de Goethe, puesta en estrecha conexión con las concepciones del mundo de la vida elaboradas por Husserl y Wittgenstein, provee incluso el hilo conductor para una crítica de la imagen del mundo derivada de la ciencia de la naturaleza de la Modernidad.

No resulta posible considerar aquí siquiera con un mínimo de detalle la concepción presentada por Goethe en su obra dedicada a los colores, elaborada a lo largo de casi cuarenta años, que en las ediciones actualmente en uso abarca varios volúmenes, y que comprende, además de un conjunto de trabajos preparatorios, una parte didáctica, una parte

\footnotetext{
${ }^{138}$ Citado por Schumann - Smith 1989 II; 639 s., 737; traducción mía.

139 Véase Rehbock 1995. Para la referencia a la polémica de Platón y Aristóteles con el atomismo, véase esp. p. 16-21.
} 
polémica y también una detallada parte histórica ${ }^{140}$. Dentro del conjunto de la obra, la parte más conocida es, sin duda, la polémica en la cual Goethe discute detalladamente la concepción de Newton, a la que opone una serie de objeciones fundamentales. Goethe mismo no consideraba central dentro de su propia concepción tal polémica con Newton, pues, como señala acertadamente Rehbock, Goethe tampoco rechazaba como un todo la nueva ciencia de la naturaleza representada ejemplarmente por Newton, sino tan sólo criticaba las exageradas pretensiones vinculadas con el pathos científico-revolucionario que imperaba a comienzos de la Edad Moderna ${ }^{141}$. En todo caso, hay buenas razones para que la polémica con Newton haya ocupado el papel protagónico en la recepción posterior de la posición de Goethe, pues es en ella donde se pone más claramente de manifiesto el aspecto de conflicto entre diferentes Weltanschauungen que involucra la cuestión debatida, desde el comienzo mismo y hasta la actualidad. Muy frecuentemente, la concepción de Goethe fue rechazada de modo apasionado como meramente diletante o bien como directamente anti-científica por parte de los defensores de una visión cientificista, y fue también defendida y ensalzada, con no menos ardor, por los críticos de dicha visión, todo ello como si se tratara de un enfrentamiento entre científicos y filósofos de la ciencia, por un lado, y poetas y filósofos reacios a la ciencia, por el otro. Como quiera que sea, actualmente se suele adoptar posiciones más matizadas, y hay defensas de una y otra posición que no responden a una división cuasi-ideológica como la antes mencionada ${ }^{142}$.

\footnotetext{
${ }^{140}$ Véase Goethe 1791-1823.

${ }^{141}$ Cf. Rehbock 1995; 44 ss., 263.

${ }^{142}$ Para una presentación resumida de la polémica sobre la base de los textos más importan-
} 
Como quiera que sea, el eje de la polémica de Goethe contra Newton se sitúa en la cuestión relativa a la relación entre la luz y los colores. Newton sostiene que la luz se compone de todos los colores que, como parece mostrar el prisma bajo las condiciones en las cuales lo empleó Newton, pueden ser (re)obtenidos por descomposición a partir de ella. Por su parte, Goethe sostiene que la luz no es compuesta sino simple, y que los colores se producen a través de la interacción de luz y oscuridad. En tal sentido, los colores no serían componentes de la luz, sino sólo efectos producidos o bien experimentados por ella (Taten und Leiden... des Lichts) ${ }^{143}$. La extensa y detallada discusión de los experimentos newtonianos y su elaboración de otros alternativos por parte de Goethe apuntan a mostrar, en definitiva, que la tesis de la composición es, en rigor, una teoría especulativa sobre la naturaleza de la luz, basada en suposiciones unilaterales, y no una genuina explicación del modo en el que surgen realmente los colores, a través de las modificaciones que experimenta la luz en diferentes interacciones.

Bien entendido, Goethe no rechaza los hechos establecidos experimentalmente por Newton, sino que critica la interpretación que Newton hace de ellos, por estar basada, a su juicio, en asunciones hipotéticas y en un ordenamiento artificioso de los fenómenos a explicar que no da cuenta expre-

tes, véase Lampert 2000; cap. I. Lampert defiende la posición de Newton. A lo largo del siglo $x x$, también como consecuencia del impacto producido por la reivindicación filosófica del mundo de la vida por parte de la fenomenología y de autores como Wittgenstein, ha habido diversos intentos de conciliación entre ciencia y mundo de la vida. En Alemania, tal ha sido la posición adoptada, entre otros, por C. Fr. von Weizsäcker y sus seguidores. Para el caso concreto de la teoría de la luz y los colores, véase, en tal sentido, el intento de conciliación llevado a cabo por Heimendahl (1961), cuya cercanía respecto de la posición de Goethe es enfatizada en el prefacio de la obra por el propio Weizsäcker (p. IX s.).

${ }^{143}$ Cf. Goethe 1791-1823 1; 45. 
samente de un conjunto de condiciones marco de las cuales se vale de modo implícito ${ }^{144}$. En apoyo de su propia tesis alega Goethe, en cambio, un amplio conjunto de observaciones que apuntan a poner de relieve la dependencia contextual del surgimiento de determinados colores, tales como, por ejemplo, el hecho de que las sombras que proyectan los objetos iluminados por el sol o por una llama, que aparecen normalmente como negras o grises, aparecen coloreadas de diversos modos, bajo condiciones contextuales diferentes, etcétera. ${ }^{145}$

Este tipo de consideración revela, de modo bastante nítido, la orientación general de la concepción de Goethe que apunta, sobre todo, a dar cuenta de la estructura, la variedad, las mutaciones de la experiencia del color, tal como ésta se da en la percepción bajo diversas condiciones contextuales. Para ello, Goethe considera todo un amplio conjunto de experimentos y elabora una cantidad de explicaciones específicas basadas en las correspondientes observaciones, y toma en cuenta, desde el comienzo, el hecho de que se trata aquí, siempre y en todos los casos, de un amplio conjunto de interacciones que involucran la luz, las cuales, en una dirección, señalan hacia el ámbito de los cuerpos físicos, sus propiedades y sus vinculaciones y, en otra dirección, hacia las condiciones fisiológicas y psíquicas o anímicas de la percepción. Ambas direcciones son, a juicio de Goethe, complementarias y no pueden ser, sin más, divorciadas a la hora de explicar los diversos fenómenos cromáticos.

${ }^{144}$ Cf. Goethe 1791-1823 3; 13-23, §§ 1-23. Para un balance crítico de las posiciones de Newton y Goethe que intenta hacer justicia tanto a las ventajas como a las limitaciones de ambas posiciones, véase Heimendahl 1961; 19-41, quien intenta incorporar ambos puntos de vista en una concepción unitaria.

${ }^{145}$ Cf. Goethe 1791-1823 2; 97 ss. 
El propio Goethe no estuvo en condiciones de determinar de modo adecuado el estatuto metódico de su concepción y, por lo mismo, tendió a verla como una alternativa excluyente a la concepción de Newton que, como tal, estaría situada en el mismo nivel de tratamiento que ésta. Pero, más allá de este hecho, lo cierto es que el veredicto de Reinach parece, en lo fundamental, acertado: al menos en lo que concierne a la parte más sustantiva de la teoría, la Farbenlehre de Goethe puede $y$ tal vez incluso debe verse como una suerte de fenomenología del color avant la lettre, que tampoco necesita presentarse como inconciliable con tales o cuales concepciones de carácter meramente físico relativas a la naturaleza y las propiedades de la luz y del color ${ }^{146}$.

\section{BIBLIOGRAFÍA}

Ash, M. G. (1995). Gestalt Psychology in German Culture 18901967. Holism and the Quest for Objectivity. Cambridge 1998 (=1985).

Böhme, G. (2003). Leibsein als Aufgabe. Leibphilosophie in pragmatischer Hinsicht. Kusterdingen 2003.

Bressan, P. (2005). «The Dark Shade of the Moon». Clinical and Experimental Ophthalmology 33 (2005); 574.

Bühler, K. (1913). Die Gestaltwahrnehmungen. Experimentelle Untersuchungen zur psychologischen und ästhetischen Analyse der Raum- und Zeitanschauung. Stuttgart 1913.

\footnotetext{
${ }^{146}$ En un sentido similar, y declaradamente en contra del modo en el que Goethe se comprendió a sí mismo, Thea Rehbock ha propuesto una interpretación de la Farbenlehre que no la presenta como una teoría científica de carácter empírico en competencia con la newtoniana, sino, más bien, como la elaboración crítica de una "gramática fenomenológica», fundada en el acceso inmediato al mundo de la vida. Véase Rehbock 1995; cap. VIII.
} 
(1918). Die geistige Entwicklung des Kindes. Jena 1918. (1922). Handbuch der Psychologie, Teil I: Die Struktur der Wahrnehmungen. Die Erscheinungsweisen der Farben. Jena 1922.

(1933a). Axiomatik der Sprachwissenschaften. Frankfurt 1933. (1933b). Ausdruckstheorie. Das System an der Geschichte aufgezeigt. Jena 1933.

(1934). Sprachtheorie. Die Darstellungsfunktion der Sprache. Jena 1934.

(1936). Das Gestaltprinzip im Leben des Menschen und der Tiere. Bern 1963.

Dessoir, M. (ed). (1925). Lehrbuch der Philosphie, Bd. II: Die Philosophie in ihren einzelnen Gebieten. Berlin 1925.

Dillon, M. C. (1998). Merleau-Ponty's Ontology. Evanston (Illinois) 21998.

Ebner, M. (2007). Color Constancy. West Sussex 2007.

Eichler, K.-D. (2010). «Wilhelm Schapps narrative Ontologie. Eine Problematisierung seiner Geschichtenphilosophie». En: Joisten 2010; 102-125.

Gelb, A. (1929). «Die Farbenkonstanz der Sehdinge». Handbuch der normalen und der pathologischen Psychologie 12 (1929); 594-678.

Gilchrist, A. (2006). Seeing Black and White. Oxford 2006.

Goethe, J. W. (1791-1823). Farbenlehre, Bd. I-V (Bd. 1: Didaktischer Teil, Bd. 2: Vorarbeiten, Bd. 3: Polemischer Teil, Bd. 4-5: Historischer Teil), ed. G. Ott - H. O. Proskauer. Stuttgart 72003 (= 1979).

Greisch, J. (2010). «Phänomenologie als Philosophie der Geschichten: eine vierte, stille Revolution der philosophischen Denkungsart?». En: Joisten 2010; 190-214.

Hardin, C. L. (1998). Color for Philosophers. Unweaving the Rainbow. Indianapolis 21993. 
Heidegger, M. (1919). «Phänomenologie und transzendentale Wertphilosophie» (1919). En: M. Heidegger, Zur Bestimmung der Philosophie, GA Bd. 56/57, ed. B. Heimbüchel. Frankfurt a. M. 1987.

Heidegger, M. (1935/36). Die Frage nach dem Ding. Tübingen 1987 (=1962).

Heidegger, M., Fink., E. (1966/67). Heraklit (1966/67), ed. W.Fr. von Herrmann. Frankfurt a. M. 21996 (= 1970).

Heimendahl, E. (1961). Licht und Farbe. Ordnung und Funktion der Farbwelt. Berlin 1961.

Hering. E. (1905). Gründzüge der Lehre vom Lichtsinn. Berlin 1920 (= Leipzig 1905).

Husserl, E. (1912-1928). Ideen zu einer reinen Phänomenologie und phänomenologischen Philosophie; Zweites Buch: Phänomenologische Analysen zur Konstitution (1912-1928), Husserliana IV, ed. M. Biemel. Den Haag 21971(= Ideen II). (1925). Phänomenologische Psychologie. Vorlesungen Sommersemester 1925, Husserliana IX, ed. W. Biemel. The Hague 1968.

(1936). Die Krisis der europäischen Wissenschaften und die transzendentale Phänomenologie (1936), Husserliana VI, ed. W. Biemel. The Hague 21976.

Joisten, K. (ed). (2010). Das Denken Wilhelm Schapps. Freiburg - München 2010.

Katz, D. (1911). Die Erscheinungsweisen der Farben und ihre Beeinflussung durch die invididuelle Erfahrung. Leipzig 1911.

(1924). «Referat zu K. Bühler, Handbuch der Psychologie, Teil I: Die Struktur der Wahrnehmungen. Die Erscheinungsweisen der Farben, Jena 1922». Psychologische Forschung 5 (1924); 171-182. (1930). Der Aufbau der Tastwelt. Leipzig 1925. 
(1930). Der Aufbau der Farbwelt. Leipzig 1930.

Koffka, K. (1924). «Perception: An Introduction to the Gestalt Theorie». Psychological Bulletin 19 (1924); 531-585.

(1925). «Psychologie». En: Dessoir 1925; 497-608. (1932). «Some Remarks on the Theory of Colour Constancy». Psychological Research 16/1 (1932); 329-354. (1935). Principles of the Gestalt Psychology. London 1935.

Kuhn, R. (1982). «Die Psychiatrie und Alexander Pfänders Phänomenologische Psychologie». En: Spiegelber, AvéLallement 1982; 51-73.

Lampert, T. (2000). Zur Wissenschaftstheorie der Farbenlehre. Aufgaben, Texte, Lösungen. Bern 2000.

Merleau-Ponty, M. (1945). Phénoménologie de la perception. Paris 1945.

Orth, E. W. (1999). Edmund Husserls 'Krisis der Europäischen Wissenschaften und die Transzendentale Phänomenologie'. Darmstadt 1999.

Pfänder, A. (1900). Phänomenologie des Wollens. Eine psychologische Analyse. München 31963 (= Leipzig 1900). (1904). Einführung in die Psychologie. Leipzig 21920 (= 1904)

(1913). «Zur Psychologie der Gesinnungen (Teil I)». Jahrbuch für Philosophie und phänomenologische Forschung I (1913); 325-404.

(1916). «Zur Psychologie der Gesinnungen (Teil II)». Jahrbuch für Philosophie und phänomenologische Forschung III (1916); 1-125.

(1924). «Grundprobleme der Charakterologie». Jahrbuch der Charakterologie I (1924); 289-335. (1933). Die Seele des Menschen. Versuch einer verstehenden Psychologie. Halle 1933. 
Rabanaque, L. R. (1993). «Campo de trasfondo y dato hylético». Ágora (Santiago de Compostela) 12/2 (1993); 7-21.

Rang, B. (1990). Husserls Phänomenologie der materiellen Natur. Frankfurt a. M. 1990.

Rehbock, Th. (1995). Goethe und die 'Rettung der Phänomene'. Philosophische Kritik des naturwissenschaftlichen Weltbildes am Beispiel der Farbenlehre. Konstanz 1995.

Reinach, A. (1913). «Über Dingfarbe und Dingfärbung». En: Schuhmann, Smith 1989 I; 365-367.

Schapp, W. (1910). Beiträge zur Phanomenologie der Wahrnehmung. Frankfurt a. M. 2004 (= 1981); edición original: Halle 1910.

Scheler, M. (1913-1916). Der Formalismus in der Ethik und die materiale Wertethik. Neuer Versuch der Grundlegung eines ethischen Personalismus, GS Bd. 2, ed. M. Scheler. Bern 61980 (= 1954).

(1923). Wesen und Formen der Sympathie, GS Bd. VII, ed. M. Frings. Bern 1973.

Schmitz, H. (1965). System der Philosphie, Bd. II/1: Der Leib. Bonn 1965.

(2008). Leib und Gefühl. Materialien zu einer philosophischen Therapeutik. Bielefeld - Locarno 32008.

(2009a). Kurze Einführung in die Neue Phänomenologie. Freibrug - München 2010 (= 2009). (2009b). Der Leib, der Raum und die Gefühle. Bielefeld Basel 22009.

Schuhmann, K., Smith, B. (eds). (1989). Adolf Reinach, Sämtliche Werke. Textkritische Ausgabe, vol. I-II. München - Hamden - Wien 1989.

Spiegelberg, H. (1972). Phenomenology in Psychology and Psychiatry. A Historical Introduction. Evanston (Illinois) 1986 (= 1972). 
Soentgen, J. (1998). Die verdeckte Wirklichkeit. Einführung in die Neue Phänomenologie von Hermann Schmitz. Bonn 1998.

Toccafondi, F. (2003). "Aufnahmen, Lesearten und Deutungen der Gestaltpsychologie». Gestalt Theory 25/3 (2003); 139-157.

Vigo, A. G. (2002). «Indiferentismo ontológico y fenomenología en la Física de Aristóteles». Noua Tellus (México) 20/2 (2002); 117-171; reproducido en Vigo 2006; 237-276. (2006). Estudios aristotélicos. Pamplona 2006.

Waldenfelds, B. (1992). Einführung in die Phänomenologie. Paderborn 1992. (2000). Das leibliche Selbst. Vorlesungen zur Phänomenologie des Leibes, ed. R. Giuliani. Frankfurt a. M. 2000. 


\section{RESUMEN}

En el presente artículo, el autor desarrolla ampliamente lo que él mismo denomina "concepciones fenomenológicas del color», elaboradas durante las primeras décadas del siglo xx. Traza las coordenadas generales de las teorías del color y los problemas filosóficos que plantean autores muy cercanos a Husserl (Schapp y Reinach) y posteriormente hace una detallada revisión de algunos representantes de corrientes psicológicas afines a la fenomenología (Carl Stumpf, Kurt Koffka, Karl Bühler, Ewald Hering, David Katz, Adhemar Gelb y otros). Finalmente, analiza dos de las posturas más representativas de la fenomenología post-husserliana: la de MerleauPonty y la de Hermann Schmitz. Además, incluye un apéndice en el que explica las teorías de Aristóteles y Goethe como dos posturas ya fenomenológicas.

Palabras clave: fenomenología del color; Schapp; Reinach; Schmitz; Merleau-Ponty.

\section{ABSTRACT}

In this paper, the author historically develops with full detail what he calls "phenomenological conceptions of color», situated all during the first decades of the twentieth century. The author traces the general coordinates of the theories of color and the philosophical problems posed by thinkers that were very close to Husserl (Schapp and Reinach), and then gives a detailed review of some representatives of psychological tendencies related to phenomenology (Carl Stumpf, Kurt Koffka, Karl Bühler, Ewald Hering, David Katz, Adhemar Gelb, and others). Finally, the author analyzes two of the 
most representative positions after Husserl's legacy: that of Merleau-Ponty and Hermann Schmitz. The author also includes an appendix that explains the theories of Aristotle and Goethe.

Key words: phenomenology of color; Schapp; Reinach; Schmitz; Merleau- Ponty. 
